\title{
Field determination of biomass burning emission ratios and factors via open-path FTIR spectroscopy and fire radiative power assessment: headfire, backfire and residual smouldering combustion in African savannahs
}

\author{
M. J. Wooster ${ }^{1,2}$, P. H. Freeborn ${ }^{1}$, S. Archibald ${ }^{3}$, C. Oppenheimer ${ }^{4,5,6}$, G. J. Roberts ${ }^{1,2}$, T. E. L. Smith ${ }^{1}$, N. Govender ${ }^{7}$, \\ M. Burton ${ }^{8}$, and I. Palumbo ${ }^{9}$ \\ ${ }^{1}$ King's College London, Environmental Monitoring and Modelling Research Group, Department of Geography, Strand, \\ London, WC2R 2LS, UK \\ ${ }^{2}$ NERC National Centre for Earth Observation, UK \\ ${ }^{3}$ Natural Resources and the Environment, CSIR, P.O. Box 395, Pretoria 0001, South Africa \\ ${ }^{4}$ Le Studium, Institute for Advanced Studies, Orléans and Tours, France \\ ${ }^{5}$ Institut des Sciences de la Terre d'Orléans, 1a rue de la Férollerie, Orléans 45071, France \\ ${ }^{6}$ Department of Geography, University of Cambridge, Cambridge CB2 3EN, UK \\ ${ }^{7}$ Scientific Services, Kruger National Park, Private Bag X402, Skukuza, 1350, South Africa \\ ${ }^{8}$ Istituto Nazionale di Geofisica e Vulcanologia, Via della Faggiola, 32-56126 Pisa, Italy \\ ${ }^{9}$ DG Joint Research Centre, Global Environment Monitoring Unit, Ispra, Italy
}

Received: 1 August 2010 - Published in Atmos. Chem. Phys. Discuss.: 1 February 2011

Revised: 20 September 2011 - Accepted: 13 October 2011 - Published: 22 November 2011

\begin{abstract}
Biomass burning emissions factors are vital to quantifying trace gas release from vegetation fires. Here we evaluate emissions factors for a series of savannah fires in Kruger National Park (KNP), South Africa using groundbased open path Fourier transform infrared (FTIR) spectroscopy and an IR source separated by $150-250 \mathrm{~m}$ distance. Molecular abundances along the extended open path are retrieved using a spectral forward model coupled to a nonlinear least squares fitting approach. We demonstrate derivation of trace gas column amounts for horizontal paths transecting the width of the advected plume, and find for example that $\mathrm{CO}$ mixing ratio changes of $\sim 0.01 \mu \mathrm{mol} \mathrm{mol}{ }^{-1}$ [10 ppbv] can be detected across the relatively long optical paths used here. Though FTIR spectroscopy can detect dozens of different chemical species present in vegetation fire smoke, we focus our analysis on five key combustion products released preferentially during the pyrolysis $\left(\mathrm{CH}_{2} \mathrm{O}\right)$, flaming $\left(\mathrm{CO}_{2}\right)$ and smoldering $\left(\mathrm{CO}, \mathrm{CH}_{4}, \mathrm{NH}_{3}\right)$ processes. We demonstrate that well constrained emissions ratios for these gases to both $\mathrm{CO}_{2}$ and $\mathrm{CO}$ can be derived
\end{abstract}

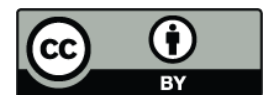

Correspondence to: M. J. Wooster (martin.wooster@kcl.ac.uk) for the backfire, headfire and residual smouldering combustion (RSC) stages of these savannah fires, from which stagespecific emission factors can then be calculated. Headfires and backfires often show similar emission ratios and emission factors, but those of the RSC stage can differ substantially. The timing of each fire stage was identified via airborne optical and thermal IR imagery and ground-observer reports, with the airborne IR imagery also used to derive estimates of fire radiative energy (FRE), allowing the relative amount of fuel burned in each stage to be calculated and "fire averaged" emission ratios and emission factors to be determined. These "fire averaged" metrics are dominated by the headfire contribution, since the FRE data indicate that the vast majority of the fuel is burned in this stage. Our fire averaged emission ratios and factors for $\mathrm{CO}_{2}$ and $\mathrm{CH}_{4}$ agree well with those from prior studies conducted in the same area using e.g. airborne plume sampling. We also concur with past suggestions that emission factors for formaldehyde in this environment appear substantially underestimated in widely used databases, but see no evidence to support suggestions by Sinha et al. (2003) of a major overestimation in the emission factor of ammonia in works such as Andreae and Merlet (2001) and Akagi et al. (2011). We also measure somewhat higher $\mathrm{CO}$ and $\mathrm{NH}_{3}$ emission ratios and factors

Published by Copernicus Publications on behalf of the European Geosciences Union. 
than are usually reported for this environment, which is interpreted to result from the OP-FTIR ground-based technique sampling a greater proportion of smoke from smouldering processes than is generally the case with methods such as airborne sampling. Finally, our results suggest that the contribution of burning animal (elephant) dung can be a significant factor in the emissions characteristics of certain KNP fires, and that the ability of remotely sensed fire temperatures to provide information useful in tailoring modified combustion efficiency (MCE) and emissions factor estimates maybe rather limited, at least until the generally available precision of such temperature estimates can be substantially improved. One limitation of the OP-FTIR method is its ability to sample only near-ground level smoke, which may limit application at more intense fires where the majority of smoke is released into a vertically rising convection column. Nevertheless, even in such cases the method potentially enables a much better assessment of the emissions contribution of the RSC stage than is typically conducted currently.

\section{Introduction}

The open combustion of biomass in forest and grassland fires is a key pathway by which humans directly affect the chemical and radiative properties of the atmosphere (Bowman et al., 2009). Its assessment generally requires spatiotemporally resolved data on smoke emissions magnitude and chemical makeup, usually obtained via multiplication of a fuel consumption estimate $[\mathrm{M}, \mathrm{kg}]$ and an emission factor $\left[\mathrm{EF}_{\mathrm{X}}\right]$, where the latter represents the amount $[\mathrm{g}]$ of chemical species $[\mathrm{x}]$ released per kg of dry fuel burned (Andreae and Merlet, 2001; Reid et al., 2009). Biomass burning emissions factors databases such as Andreae and Merlet (2001) and Akagi et al. (2011) usually list averages or ranges of $\mathrm{EF}_{\mathrm{X}}$ for many different species, often themselves derived from smoke emission ratio measures $\left(\mathrm{ER}_{\mathrm{x} / \mathrm{y}}\right.$, the relative excess amounts of two smoke species $[\mathrm{x}]$ and $[\mathrm{y}])$. Many laboratory and field studies have contributed to generating $\mathrm{ER}_{\mathrm{x} / \mathrm{y}}$ and $\mathrm{EF}_{\mathrm{x}}$ databases, along with relationships between these and metrics such as the modified combustion efficiency [MCE; the ratio of emitted $\mathrm{CO}_{2}$ to $\mathrm{CO}+\mathrm{CO}_{2}$ ] (e.g. Yokelson et al., 1996). However, since uncertainties in $\mathrm{EF}_{\mathrm{x}}$ propagate linearly into uncertainties in derived emissions magnitude, improvements in our understanding of emissions factors and their spatio-temporal variation are still required (Korontzi et al., 2003). Such improvements probably become more necessary as satellite-derived burned area and fire radiative power (FRP) products related to large-area wildfire fuel consumption become more mature (e.g. Roy et al., 2008; Freeborn et al., 2009; Giglio et al., 2009; Kaiser et al., 2009; Xu et al., 2010; van der Werf et al., 2010).

Emissions factors and emissions ratios for many biomass burning species actually fluctuate over wide ranges, even within similar fuel types. See for example the $\sim \times 10$ variation in $\mathrm{EF}_{\mathrm{CH}_{4}}$ for coniferous fuels noted in Yokelson et al. (1996) as a function of MCE, and the $\sim \times 3$ variation noted for African savannahs in Ward et al. (1996) for $\mathrm{EF}_{\mathrm{CO}}$ and $\mathrm{EF}_{\mathrm{CH}_{4}}$. Such variability is related to factors such as the ratio of live to dead fuel, its arrangement and moisture content, environmental condition and fuel elemental (e.g. nitrogen) makeup (Keene et al., 2006). To move beyond smallscale laboratory studies and help probe emissions variability at the sites of larger-scale open fires, Griffith et al. (1991) demonstrated the use of open-path Fourier transform infrared (FTIR) spectroscopy operated in so-called "extended" or "long-path" mode (Gosz et al., 1988; Griffith et al., 1991). This approach allows for the detailed sampling of smoke transported downwind of the fire and integrated across pathlengths of tens or hundreds of meters, albeit only that lying relatively close to the ground rather than in strongly lofted columns. Whilst ground-based in situ point sampling using grab bags or other smoke collection devices offers the potential advantage of characterizing ground-level smoke related to a specific fuel type or process (smouldering/flaming), the spatially-integrated sampling available from the extended OP-FTIR geometry offers the potential to be significantly more "site-integrated", whilst still allowing low level smoke emitted during different fire "stages" (e.g. backfire, headfire, and residual smouldering combustion) to be individually characterised.

Since the first demonstration by Griffith et al. (1991), extended OP-FTIR has been little used in open biomass burning studies, perhaps in part because of a perceived difficulty in deployment. Since then the size, mass and cost of OPFIR systems have reduced significantly, and they are now quite commonly deployed during studies of ambient and polluted air, industrial and volcanic plumes (e.g. Gosz et al., 1998; Hren et al., 2000; Bacsik et al., 2006; Oppenheimer and Kyle, 2007). A re-appraisal of the OP-FTIR approach in relation to biomass burning studies, and a review of its ability to probe inter- and intra-fire variations in emissions chemistry is therefore timely, particularly so since the weakly lofted emissions resulting from residual smouldering combustion (RSC) are now seen as potentially significant in some ecosystems (Bertschi et al., 2003; Christian et al., 2007). Such low level smoke is very well targeted by extended open path geometries, and here we demonstrate the capability of the OP-FTIR technique to probe emissions from a series of 7 ha fires conducted in Kruger National Park (KNP), a key fire-prone savannah environment in southern Africa (Govender et al., 2006). For these fires we present long-path, spatially integrated measurements of the weakly lofted emissions resulting from RSC, and from spreading headfires and backfires, and compare the $\mathrm{ER}_{\mathrm{x} / \mathrm{y}}$ and $\mathrm{EF}_{\mathrm{x}}$ measures derived from these observations to those calculated previously for the same study area using ground-based in situ sampling and also airborne measurements of lofted smoke. 


\section{Background and specific study aims}

\subsection{Measurements of laboratory and open fire plumes}

Smoke emission ratios, emissions factors and combustion efficiencies can be derived from trace gas concentrations measured using a variety of approaches. Delmas et al. (1995), Goode et al. (2000), Andreae and Merlet (2001) and Koppmann et al. (2005) include detailed reviews of each method, with laboratory combustion chamber experiments being probably the most common. Here total gas flux can be accurately logged to determine fuel consumption via the carbon mass balance approach, enabling direct calculation of $\mathrm{EF}_{\mathrm{x}}$ for the separate flaming and smouldering processes and calculation of so-called "fire-averaged" values (Yokelson et al., 1996). A weighted mean approach based on direct measurement of the fuel mass consumed in each combustion process is also possible, though potentially confounded by the evaporation of fuel moisture. Whatever the method used, laboratory-scale experiments can, however, produce fire characteristics that differ substantially from natural behaviour, potentially resulting in EF biases (Delmas et al., 1995; Fernández-Gómez et al., 2011). Trace gas measurements at open vegetation fires are therefore greatly valued, but can be difficult to acquire due to the hazardous, highly dynamic and sometimes unpredictable nature of fire. Furthermore, in open fires all combustion processes may occur simultaneously, with emissions released into one or more "integrating" plumes. Airborne campaigns sample the lofted parts of such plumes and offer many practical and scientific benefits (e.g. Yokelson et al., 1999, 2003; Sinha et al., 2003, 200b). However, since the relative amount of fuel consumed in each combustion process is generally unknown when relying on aircraft observations, it must be assumed that natural processes provide the appropriate mixing required to estimate "fire averaged" ER and EF measures (Andreae and Merlet, 2001). Point-based ground sampling of smoke generally targets more weakly lofted emissions, and by necessity often those from the less intense parts of the fire since these are the safest to approach, but offer the advantage of being perhaps more easily associated with particular fuel consumption measures and/or combustion processes or fire stages. Ground sampling has most commonly involved canister or grab bag collection for subsequent laboratory analysis, but use of field-deployed open path spectroscopic methods potentially avoids the problem of within-canister chemical conversion or wall-loss that can be associated with smoke collection techniques (Goode et al., 2000; Yokelson et al., 2003), and can provide measurements relating to substantial pathintegrated "transects" through the smoke, rather than to individual points.

\subsection{Smoke plume analysis using FTIR techniques}

Field-deployed spectroscopic methods based on FTIR techniques potentially allow a single instrument to provide the infrared spectra from which a wide range of smoke gases can be simultaneously and continuously measured, potentially at detection limits of $\sim 5-20$ parts per billion or better over $\sim 100 \mathrm{~m}$ pathlengths (or the equivalent created via use of a multi-path reflector; Griffith et al., 1991; Yokelson, 1996, 1999, personal communication, 2011). This ability to target multiple gases simultaneously may be critical for discerning intra- and inter-fire emissions ratio variability. However, FTIR-based studies of biomass burning smoke have most commonly used so-called closed-path/extractive techniques, or open path methods covering relatively short $(<1-10 \mathrm{~m})$ distances (e.g. Goode et al., 2000; Yokelson et al., 1996; 1999; Bertschi et al., 2003; Christian et al., 2007; Castro et al., 2007; Fernández-Gómez et al., 2010; Burling et al., 2010). Whilst these studies have been extremely productive, sample representativeness may still be a concern, and hazardous areas of higher intensity (flaming) combustion can be difficult to measure. Griffith et al. (1991) first illustrated use of an extended open path geometry in biomass burning studies, where the FTIR spectrometer and IR source are separated by potentially hundreds of meters and positioned such that the advected smoke passes through the long optical path. Along with the standard FTIR benefits outlined above, this extended measurement geometry is not limited to sampling only more approachable parts of the fire, and provides a "spatially-integrated" overview of the weakly lofted combustion products that is to acquire with other ground-based techniques (Griffith et al., 1991).

\subsection{Aims of the current study}

Despite their potential, extended OP-FTIR methods have been little used in biomass burning studies since Griffith et al. (1991). Here we describe a new extended OP-FTIR deployment in the arid savannah of Southern Africa, an environment which together with the more moist humid woody savanna is annually responsible for perhaps a quarter of global fuel consumption (van der Werf et al., 2003; Roberts et al., 2009; Archibald et al., 2010). We use the approach to derive individual ER and EF measures for the different stages of these savannah fires, comparing these to previous estimates made for similar fires conducted in the same study area using alternative measurement approaches; including airborne campaigns targeting lofted plumes. Simultaneous with our OP-FTIR measurements we deploy a thermal imaging camera on a hovering helicopter to provide airborne fire radiative power (FRP) measurements, allowing the relative amount of fuel burned in each stage of each fire to be calculated and used to determine the "fire averaged" emission ratios and emission factors via weighted averages of the per-stage measures. We use these results to investigate the 
Table 1. Description of the four 7-ha open vegetation fires studied in this work, conducted 27-28 August 2007 at the Kruger National Park (KNP) experimental burn plots detailed in Govender et al. (2006) and located within the latitude-longitude range (25.10-25.16 ${ }^{\circ}$ S), (31.2$\left.31.4^{\circ} \mathrm{E}\right)$. The N'waswitshaka and Skukuza plots were located close to Skukuza $\left(25.1097^{\circ} \mathrm{S}, 31.4172^{\circ} \mathrm{E}\right)$, whist the Numbi and Shabeni plots were located close to Pretoriuskop $\left(25.1639^{\circ} \mathrm{S}, 31.234^{\circ} \mathrm{E}\right)$. A general description of the KNP geology and vegetation is provided in Scholes et al. (2001), whilst Disney et al. (2011) provide a detailed description of these particular experimental plots.

\begin{tabular}{|c|c|c|c|c|c|c|c|c|}
\hline & $\begin{array}{l}\text { Plot } \\
\text { Name }\end{array}$ & $\begin{array}{l}\text { Fuel Load } \\
\text { Fuel Consumed } \\
\left(\text { mean } \pm \mathrm{s} \mathrm{d} ; \mathrm{g} \mathrm{m}^{-2}\right) \\
\text { Fuel Moisture }(\%)\end{array}$ & $\begin{array}{l}\text { First } \\
\text { Ignition } \\
\text { (local time) }\end{array}$ & $\begin{array}{l}\text { FTIR to } \\
\text { IR Source } \\
\text { Distance (m) }\end{array}$ & $\begin{array}{l}\text { Air } \\
\text { Temp }\left({ }^{\circ} \mathrm{C}\right)\end{array}$ & $\mathrm{RH}(\%)$ & $\begin{array}{l}\text { Air Pressure } \\
(\mathrm{mb})\end{array}$ & $\begin{array}{l}\% \text { Fuel } \\
\text { Burned in } \\
\text { Backfire: } \\
\text { Headfire: } \\
\text { RSC Stages }\end{array}$ \\
\hline Fire 1 & N'was* & $\begin{array}{l}184 \pm 57 \\
101 \pm 82 \\
13.1 \%\end{array}$ & $14: 01 \mathrm{~h}$ & 170 & 23 & 23 & 962 & $12: 87: 1$ \\
\hline Fire 2 & Skukuza & $\begin{array}{l}144 \pm 45 \\
94 \pm 58 \\
16.6 \%\end{array}$ & 09:40 h & 234 & 20 & 36 & 973 & 8:91:1 \\
\hline Fire 3 & Numbi & $\begin{array}{l}374 \pm 199 \\
309 \pm 238 \\
11.5 \%\end{array}$ & $13: 20 \mathrm{~h}$ & $\begin{array}{l}150 \\
\text { (estimate) }\end{array}$ & 30 & 26 & 941 & $2: 96: 2$ \\
\hline Fire 4 & Shabeni & $\begin{array}{l}147 \pm 120 \\
115 \pm 127 \\
19.5 \%\end{array}$ & $09: 59 \mathrm{~h}$ & 200 & 30 & 45 & 943 & - \\
\hline
\end{tabular}

*Abbreviation of "N'waswitshaka"

importance of the RSC stage for this savannah ecosystem, and finally we comment on the overall utility of extended OP-FTIR deployments for probing biomass burning smoke emissions in the field.

\section{Methodology}

\subsection{Study area and measurement methods}

We studied four 7 ha burns (referred to here as Fires 1 to 4 ) ignited in Kruger National Park (KNP: South Africa), whose fuel and fire history is detailed in, for example, Stocks et al. (1996) and Archibald et al. (2010). The measurement campaign took place in August 2007, towards the peak of the regions fire season, and each fire was a perimeter ignition event conducted in one of the long-term experimental burn plots detailed in Govender et al. (2006). These KNP burn plots have been previously used in ground-based emissions studies based on point-based measurement methods (e.g. Ward et al., 1996), and KNP has also been the site of a number of airborne smoke sampling campaigns (e.g. Sinha et al., 2003). These past works provide useful emission ratio and emissions factor statistics for comparison to our results. Each 7 ha burn plot was rectangular $(\sim 380 \mathrm{~m} \times 180 \mathrm{~m})$ and had its fuel characteristics and fuel consumption estimated via pre- and post-fire in situ destructive sampling (Table 1). Whilst there were many standing trees on each plot (e.g.
Combretum, Sclerocaryabirrea, and Terminaliasericea), fire appeared to leave most unaffected, and grasses (which here can exceed $1 \mathrm{~m}$ height) provided the bulk of the consumed fuel, with the remainder dominated by leaf litter and woody debris. Shea et al. (1996) previously described around three quarters of the fuel consumed in these KNP plots as being grasses. Further plot descriptions, example pre- and post-fire aerial photography and matching scene simulations can be seen in Disney et al. (2011) related to a subsequent (2008) field campaign.

During each burn, meteorological conditions were logged using a portable weather station positioned upwind, whilst smoke emissions were probed using the OP-FTIR system positioned downwind. Simultaneously with this, radiative energy emissions from the burning fuel were assessed using a infrared thermal imaging camera positioned on an overhead helicopter, from which an optical video record was also collected. This measurement layout is shown in Fig. 1.

Each burn plot was first ignited with a backfire (e.g. north and west sides of the plot shown in Fig. 1), in part to create a larger fire break at the downwind side. This was followed some min later by the headfire ignition at the upwind side (e.g. South and East sides of plot shown in Fig. 1). Lacaux et al. (1996) characterised a typical headfire plume as containing emissions from both the flaming front and a "smoking" zone located immediately behind, and this type of process was clearly seen in much of the fire activity (e.g. Fig. 2a). 


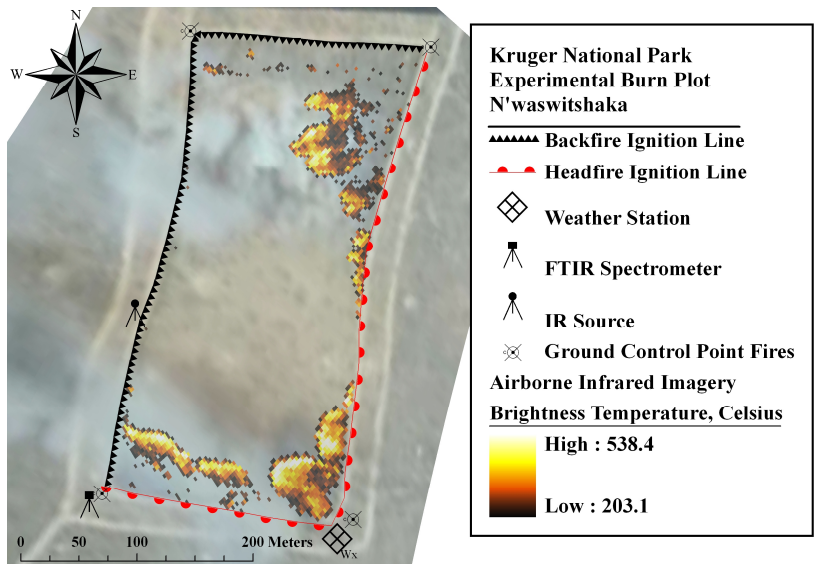

Fig. 1. Typical field setup deployed here to study the smoke characteristics of southern African savannah fires using OP-FTIR spectroscopy. Data are from a period less than halfway through the duration of Fire 1 (Table 1), when the flaming front had only transited across approximately one quarter of the total plot area. Background view is a frame captured from the near vertically-viewing optical video record made from the hovering helicopter, where the burn plot can be seen to be surrounded by a semi-rectangular fire break (leading to a dirt road bottom left). The smoke plume (grey) generated here mainly by the head fire lit on the eastern and southern sides of the plot, can be seen blowing toward the west. Superimposed on this optical image is the map of pixel brightness temperatures recorded via an airborne AGEMA-550 infrared camera. Only the locations of ground pixels whose IR brightness temperature (BT) exceeds $203^{\circ} \mathrm{C}(476 \mathrm{~K})$ are displayed, corresponding to areas of active combustion. Higher BTs are generally seen at the fire fronts (likely flaming areas), whereas lower BTs are recorded behind the fronts, i.e. in the "smoking zone" identified by Lacaux et al. (1996) where combustion rate and thus heat release is lower (Fig. 2). It should be noted that BTs are unlikely to represent actual fire temperatures since the flames may under-fill pixels (see e.g. Wooster et al., 2005). The smoke plumes can be seen to emanate from areas of active combustion identified by the IR-camera record. The backfire (downwind) and headfire (upwind) ignition lines are indicated, as is the location of the FTIR spectrometer, IR source and weather station. All imagery and spatial locations were positioned using GPS records and/or ground control points identified in either the optical or IR camera records. From the shadow of the plume on the ground, and the location of the sun, the plume height over the plot is estimated at $\sim 50 \mathrm{~m}$.

The flaming front was easily identified as a group of pixels showing strongly elevated brightness temperatures in the thermal imagery (see Fig. 1), and its movement across the plot was easily tracked. Combustion associated with the passage of the flaming front usually ceased when the headfire reached the downwind plot boundary and/or the area already burnt out by the backfire, typically $\sim 30 \mathrm{~min}$ after ignition, though on some plots smoke production from areas of residual smouldering combustion (RSC; Bertschi et al., 2003) continued for many minutes.

\subsection{Fire radiative power measurement}

During each fire, a GPS-equipped helicopter hovered some hundreds of meters above and slightly to the side of each plot, enabling aerial recording of each fire event over the entire plot area. The thermal camera used was an AGEMA550 middle infrared (MIR) imager, which recorded the fires radiant energy emission signature across a $320 \times 240$ pixel imaging array. A narrowband filter centred at $3.9 \mu \mathrm{m}$ was fitted to prevent detector saturation over high intensity fire pixels. Mean ground pixel size across the $40^{\circ} \times 30^{\circ}$ fieldof-view was $1.5-2.5 \mathrm{~m}$, depending upon flying height, calculated using the viewing distance and angle from the helicopter to the plot as determined from the GPS records. The brightness temperatures recorded by the AGMEA were converted into spectral radiances and then to per-pixel measures of fire radiative power (FRP) using the MIR radiance method of Wooster et al. (2003). For each IR imaging frame, the FRP for each detected fire pixel was summed to provide an instantaneous, plot-integrated and time-stamped FRP measure. This FRP time-series was generated at 5-s intervals for the entire fire duration. Full details of this processing approach are given in Wooster et al. (2005) and Freeborn et al. (2008). A standard $25 \mathrm{~Hz}$ digital video camera was mounted alongside the AGEMA-550 to provide a matching optical video record.

The direction of the flaming front and the plume can both be determined from the airborne optical and thermal video record in a somewhat similar manner to that previously used to distinguish backfires and headfires in satellite data records (Smith and Wooster, 2005). These video records were therefore used to track the movement of the active fire front and smoke plume, and to confirm the fire ignition and extinction times reported by the field team. Based on these timings, we separated data of each burn into three 'stages', based on reports from the ground observers and analysis of the optical and thermal IR airborne imagery. Firstly the "backfire" stage, when only the backfire was burning (fire front moving against the wind), and secondly the "headfire" stage that commenced immediately after headfire ignition (fire front moving with the wind). The flaming front of the headfire moved across each plot much more rapidly (typically $\sim 5 \times$ to $20 \times$ faster) than that of backfire (as noted previously by Lacaux et al., 1996), and thus headfire emissions soon dominated smoke production when headfires and backfires burned simultaneously after headfire ignition (Fig. 2b). Following Bertschi et al. (2003), we define the third "RSC" stage (Fig. 2c) as the period of continued smoke production after the cessation of a significant and spreading flame front.

\subsection{OP-FTIR data collection}

The FTIR system deployed in KNP was a MIDAC Open Path Air Monitoring System (MIDAC Corporation, Irvine CA) equipped with a $76 \mathrm{~mm}$ Newtonian telescope to deliver a $\sim 9$ - 

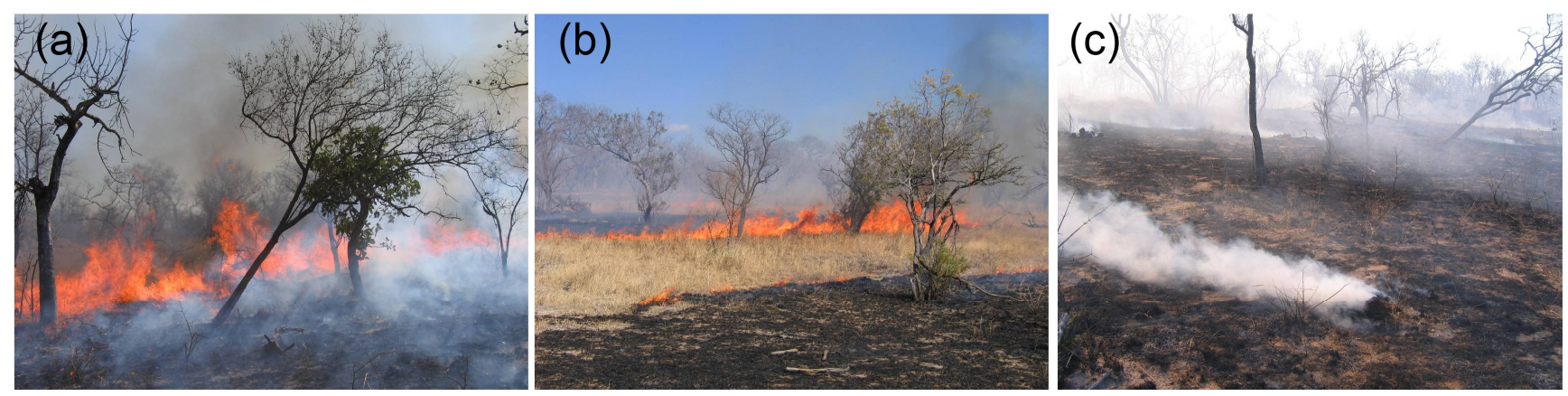

Fig. 2. Example photographs of the savannah burns studied here, taken during (a) the headfire stage of Fire 1 (N'waswitshaka) and (b) the headfire stage of Fire 2 (Skukuza). Two flame fronts are seen in (b), the still existing backfire flame front that is closest to the camera, and the more distant headfire flame front that is clearly more intense, with higher flame heights and a more rapid rate of spread. The headfire flame front therefore consumes more fuel and produces more emissions per unit time than does the backfire flame front, and thus dominates smoke production during the headfire stage. Also note the apparently more substantial "smoking zone" in (a) in comparison to (b). Photograph (c) is also of the N'waswitshaka plot (Fire 1) during the subsequent RSC stage. This demonstrates the effect that elephant dung located in the plot interior had on the amount of smouldering combustion, which is expected to have contributed significantly to emissions from the headfire "smoking zone" seen in (a). Dung ignited at the start of the burn was seen to smoulder, and sometimes even flame, well into the RSC stage.
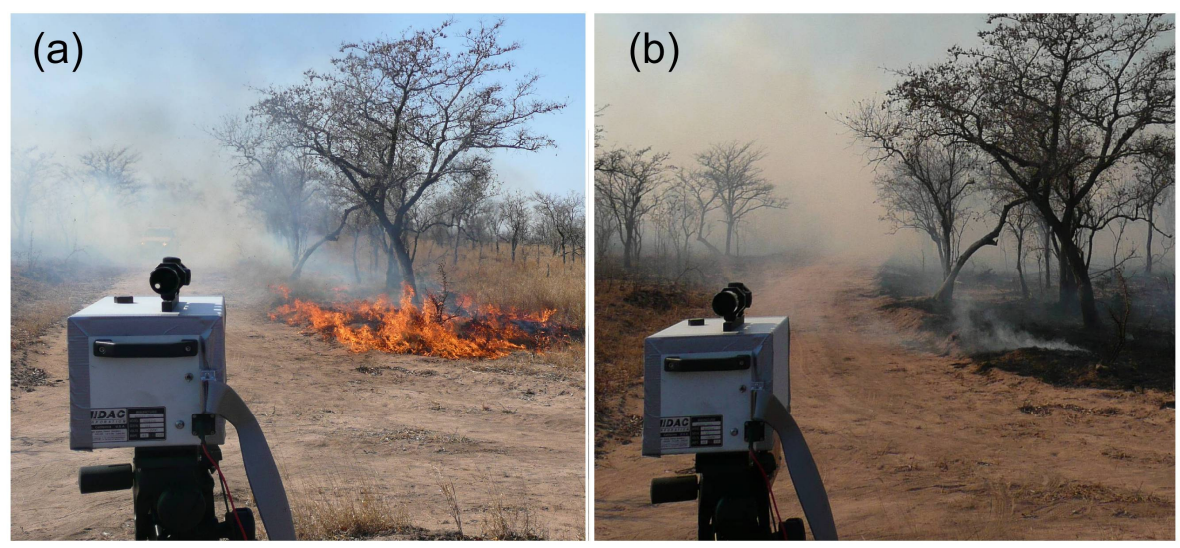

Fig. 3. Photography of the OP-FTIR deployment in Kruger National Park, looking from the FTIR spectrometer towards the IR source. Matching the geometry shown in Fig. 1, the spectrometer is located at the south-west corner of the plot and views northwards, targeting the IR source located $150 \mathrm{~m}$ or more away along the western plot edge. (a) Shows the situation shortly after backfire ignition, and (b) towards the end of the residual smouldering combustion (RSC) stage. Smoke is driven by the predominately westerly wind through the long optical path between the spectrometer and IR source. The source cannot be seen visually in these optical wavelength images due to scattering and obscuration by sub-micron sized smoke particulates, though this did not significantly impact the total energy signal recorded by the IR spectrometer (which measures at wavelengths $>2.5 \mu \mathrm{m}$ ). Note the almost complete replacement of the grass fuel by char and ash in (b), but the apparently very limited fire impact on the larger trees.

mrad field-of-view. It was deployed at head height slightly downwind of each burning plot and set to view a battery powered IR source (a tripod-mounted $1275^{\circ} \mathrm{C}$ silicon carbide glower located at the focus of a $\sim 50 \mathrm{~cm}$ gold plated aluminium reflector) located $\sim 150-250 \mathrm{~m}$ away along the plot edge. Longer optical paths are achievable with this system, but in KNP these were blocked by trees and undulating terrain. The quantity of smoke in the optical path was sufficient to completely obscure the IR source when viewed with the naked eye from the spectrometer location (Fig. 3), and the extended pathlength provided spatially integrated measurements across much of the width of the horizontally advected smoke plume (Fig. 1).

The Open Path Air Monitoring System was fitted with a mercury-cadmium-telluride (MCT) detector to collect spectra covering the shortwave infrared (SWIR) to thermal infrared (TIR) spectral range $\left(670-5000 \mathrm{~cm}^{-1} ; 15-2.0 \mu \mathrm{m}\right)$, and Stirling-cycle detector cooling was used to avoid the 


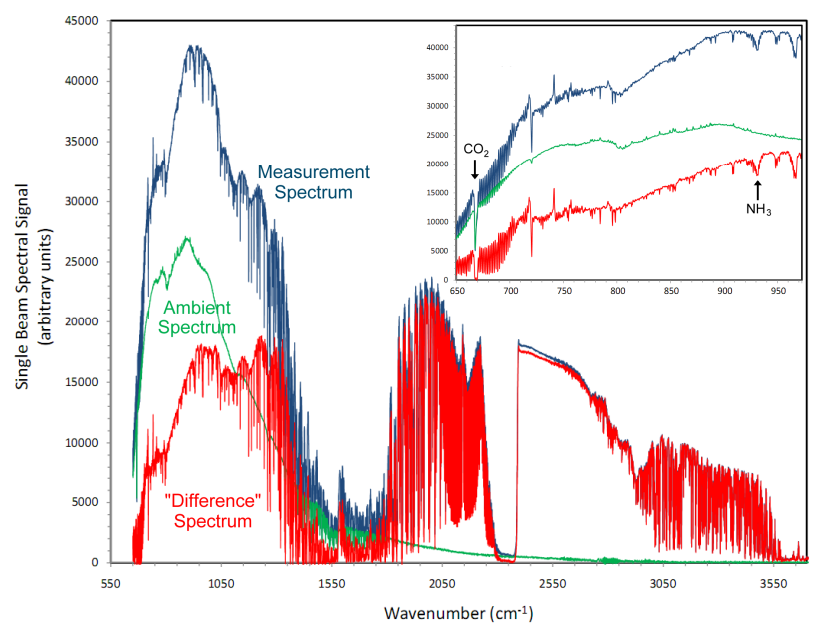

Fig. 4. Single beam measurement spectrum (blue) collected by the FTIR spectrometer viewing the IR Source across a $170 \mathrm{~m}$ smokefilled optical path during Fire 1. Also shown is an "ambient" spectrum (green) collected without the IR source, together with the resulting "difference" spectrum (red) calculated according to Müller et al. (1999) to remove the effect of ambient emission (including instrument self-emission) from the measurement spectrum prior to trace gas retrieval. The inset focuses on the spectral range where the ambient spectrum has most significance (i.e. lower wavenumbers). The $668-670 \mathrm{~cm}^{-1} \mathrm{CO}_{2}$ absorption band is correctly seen to show zero signal in the "difference" spectrum, whilst the primary 925-934 $\mathrm{cm}^{-1}$ absorption feature used here to retrieve $\mathrm{NH}_{3}$ column amounts is clearly apparent in both the measurement and difference spectra.

need for liquid nitrogen. The cooled detector, instrument electronics and spectrometer mechanical assemblage were encased in a light, sheet metal casing ( size $=356 \times 183 \times$ $166 \mathrm{~mm}$; mass $\sim 9.5 \mathrm{~kg}$ ) powered by a $12 \mathrm{v}$ battery and controlled by a laptop computer through a dedicated PCMCIA interface. We recorded raw interferograms (IFGs) at the highest available spectral resolution of the instrument $\left(0.5 \mathrm{~cm}^{-1}\right)$, with 8 consecutive scans averaged together (to improve $S / N$ ) to give an 8 -s acquisition time step.

\subsection{Retrieval of trace gas abundances from OP-FTIR spectra}

\subsubsection{Spectral pre-processing}

The co-added IFGs collected by the OP-FTIR system were zero-filled by a factor of 2 and had a Mertz phase correction and triangular apodization function applied prior to conversion to single beam (SB) spectra via a Fourier transform (Smith et al., 1996). This pre-processing was enacted in the AutoQuant Pro control and analysis software (MIDAC Corporation, Irvine, CA). Figure 4 shows two examples of the resulting SB spectra collected in the field using the OP-FTIR system. Shown are one "measurement" spectrum, collected
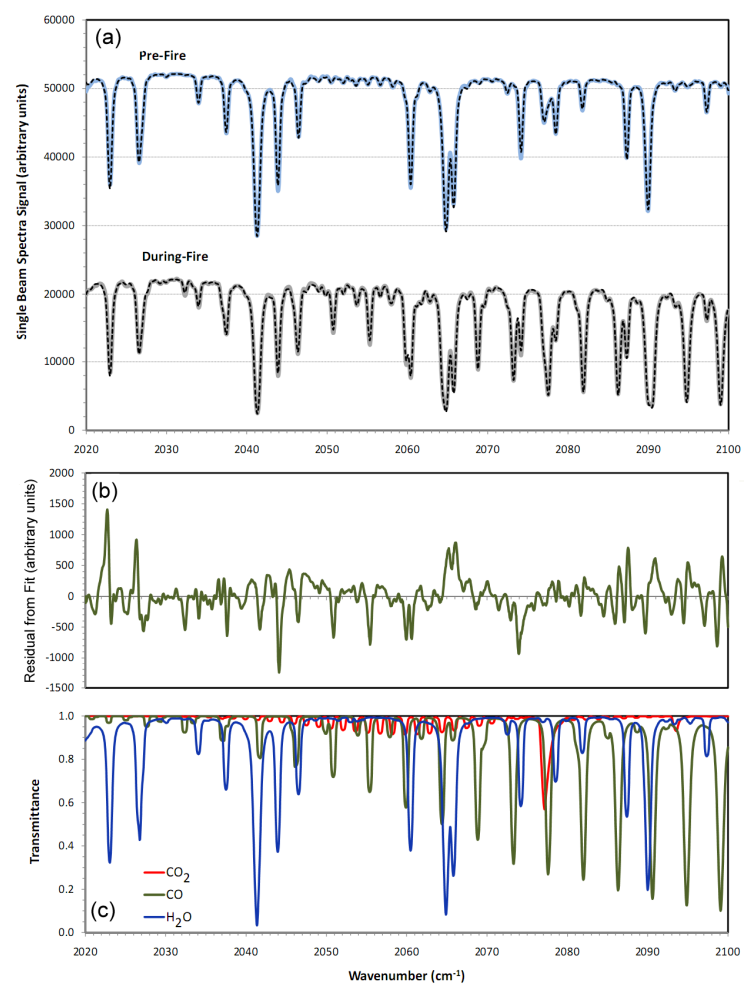

Fig. 5. Open path FTIR single beam spectra and best-fit forward modelled spectra for two example measurements recorded during Fire 1 (Table 1). Spectra were recorded by the deployed FTIR spectrometer operating in extended open path mode at $0.5 \mathrm{~cm}^{-1}$ wavenumber resolution, and the spectral window shown is the 2020-2100 $\mathrm{cm}^{-1}$ range used here for retrieval of $\mathrm{CO}_{2}$ and $\mathrm{CO}$ abundances (Table 2). (a) Examples of single beam spectra measured both prior to and subsequent to fire ignition, with the best-fit forward modelled spectra calculated using the retrieval procedure of Burton (1998) overlain in each case (dashed lines). The pre-fire and during-fire spectra correspond, respectively, to times 5 and $22 \mathrm{~min}$ into the trace gas time series shown in Fig. 6. Pre- and duringfire spectra are shown offset for clarity. Note the greater number of strong absorption features in the during-fire spectra, caused by the increased within-plume trace gas abundances. (b) The residual of the measured and best-fit forward modelled "during fire" spectra shown in (a), indicating that no significant spectral features remain unfitted and confirming the strong agreement between the measured and forward-modelled spectra seen in (a). Retrievals of $\mathrm{CO}_{2} / \mathrm{CO}$ column amounts from the pre-fire and during-fire spectra are equivalent to the ratio of path averaged mixing ratios (in ppmv) of 396/0.043 (pre-fire) and 758/25.1 (during-fire) respectively. (c) The transmittance spectrum of the best-fit $\mathrm{CO}_{2}, \mathrm{CO}$ and $\mathrm{H}_{2} \mathrm{O}$ column amounts calculated from the during-fire spectra shown in (a). The product of these transmittances and the background polynomial provides the best-fit modelled spectra already shown in (a). Other gases (e.g. $\mathrm{N}_{2} \mathrm{O}, \mathrm{O}_{3}$, OCS) having absorption features within this spectral window were included in the fit, but none were found in significant quantities. 
whilst viewing the IR source horizontally through the smoke, and one "ambient" spectrum collected along the same path but without the IR source. In order to maximise the accuracy of the trace gas retrievals, "ambient" spectra such as this were used to correct each "measurement" spectra for thermal emission contributions from the instrument and the ambient background (see Müller et al., 1999 and Sect. 3.4.3).

\subsubsection{Trace gas retrieval procedure}

Trace gases within the OP-FTIR optical path were identified and quantified based on IR spectral signatures seen in particular regions of the recorded SB spectra (Fig. 5a). Briz et al. (2007) review the methods available to retrieve trace gas abundances from such spectra, concluding that approaches based on spectral forward models may be most effective in removing the need for a clean "background" spectrum and for avoiding problems with non-linear departures from the Beer-Lambert Law (Childers, 2001). We use such a forward modelling approach, based on a retrieval algorithm described in detail by Burton (1998) and Horrocks et al. (2001). The approach is used with each SB spectrum to provide an estimate of the total number of molecules of the target gas species $[\mathrm{x}]$ per unit area along the horizontal observation pathlength (molecules $\mathrm{cm}^{-2}$ ), here termed the "column amount". The retrieval algorithm is a combination of the Atmospheric Radiation Reference Forward Model (RFM v4.0 available at www.atm.ox.ac.uk/RFM/; Edwards and Dudhia, 1996), the HITRAN 2008 [and updates] spectral database (a compilation of spectroscopic parameters for 42 atmospheric molecules; Rothman et al., 2009), the optimal estimation procedure of Rodgers et al. (1976), and the enhanced nonlinear fitting procedure of Marquardt (1963). The importance of using an up-to-date version of HITRAN was indicated by the fact that testing against retrievals made with HITRAN 1996 produced carbonaceous gas column amounts a little $(\sim 5 \%)$ higher for all gases, except in the case of formaldehyde where the increase was much more significant $(\sim 35 \%)$. This resulted in, for example, $\mathrm{ER}_{\mathrm{CO} / \mathrm{CO}_{2}}$ values lower by around $8 \%$ when using HITRAN 2008 as compared

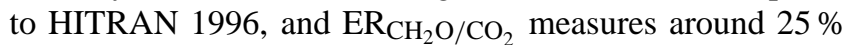
higher. These effects should be borne in mind when comparing results from current HITRAN-based FTIR studies to those from prior studies whose retrievals were based on older databases, though the review of biomass burning emissions factors provided by Akagi et al. (2011) apparently already contains the appropriate adjustments (R. Yokelson, personal communication, 2011). The OP-FTIR retrieval algorithm of Burton (1988) is initialised with the atmospheric temperature, pressure, optical path length and the a priori column abundances of a set of target gases that have IR absorption features located within a specified spectral window of interest (e.g. the $2020-2100 \mathrm{~cm}^{-1}$ region used to retrieve column abundances of $\mathrm{CO}_{2}$ and $\mathrm{CO}$ as shown in Fig. 5). The optical path can be considered to be composed of two "layers" if
Table 2. Spectral windows used for the forward model-based retrieval of biomass burning plume trace gas column amounts from the measured single beam FTIR spectra, selected from those used in previous closed-path biomass burning studies (e.g. Yokelson et al., 1997; Goode et al., 2000). Potentially interfering species (most importantly water vapour) were also included in the forward model parameterisation.

\begin{tabular}{lr}
\hline Trace Gas Species & Retrieval Spectral Window \\
\hline Carbon dioxide $\left(\mathrm{CO}_{2}\right)$ & $2020-2100 \mathrm{~cm}^{-1}$ \\
and Carbon monoxide $(\mathrm{CO})$ & \\
Methane $\left(\mathrm{CH}_{4}\right)$ & $3010-3100 \mathrm{~cm}^{-1}$ \\
Formaldehyde $\left(\mathrm{CH}_{2} \mathrm{O}\right)$ & $2720-2840 \mathrm{~cm}^{-1}$ \\
Ammonia $\left(\mathrm{NH}_{3}\right)$ & $900-940 \mathrm{~cm}^{-1}$ \\
\hline
\end{tabular}

necessary, e.g. the plume and the ambient atmosphere, which each having different temperatures and trace gas amounts. This is similar to the approach used in the Multiple Atmospheric Layer Transmission model (MALT) of Griffith et al. (1996). For each species included in the fitting procedure, the transmission of IR radiation along the open path is calculated using the forward model (Fig. 5c). This output is used to derive a modeled SB spectrum to compare to the measured SB spectrum (Fig. 5a), and a non-linear least squares fitting routine used to minimize the fit residuals (Fig. 5b) by iteratively adjusting the trace gas abundances used within the simulation. Being similar in design to the widely used SFIT code (Niple et al., 1980; Benner et al., 1995) and the Multiple Atmospheric Layer Transmission model (MALT; Griffith et al. 1996), the Burton (1998) code has been used in many studies, in particular of volcanic plumes (e.g. Francis et al., 1998; Burton et al., 2000; Oppenheimer and Kyle, 2007).

The focus of our work in KNP was the retrieval of the primary carbonaceous species emitted preferentially during the three key processes of vegetation combustion (pyrolysis, flaming, smouldering), and the calculation of their emissions ratio and emissions factors. Of course, the production of each of these compounds is not limited to only one of these combustion processes (Lobert and Warnatz, 1993), but the amount of each species released per unit of fuel mass burned (i.e. the emissions factor) can vary considerably between processes, and we use the definitions of Yokelson et al. (1996) to classify each as a flaming $\left(\mathrm{CO}_{2}\right)$, smoldering $\left(\mathrm{CO}, \mathrm{CH}_{4}\right)$ or pyrolysis $\left(\mathrm{CH}_{2} \mathrm{O}\right)$ product. In addition to these carbonaceous species, we also searched the IR spectra for signs of nitrogenous compounds. $\mathrm{N}_{2} \mathrm{O}$ could not be readily detected above background levels, in agreement with other findings (e.g. Griffith et al., 1991). Absorption features for $\mathrm{NO}$ (around $1900 \mathrm{~cm}^{-1}$ ) and $\mathrm{NO}_{2}$ (around $2920 \mathrm{~cm}^{-1}$ ) were detectable in some but not all of the recorded SB spectra, most commonly those measured during periods of higher trace gas column amounts. Ammonia, a nitrogenous species emitted preferentially during smouldering processes, was the 
most readily detected $\mathrm{N}$ species, in apparent agreement with Griffith et al. (1991) and Yokelson et al. (1997). In addition to the four carbonaceous species, we therefore retrieved $\mathrm{NH}_{3}$ column amounts from all our measured spectra. Table 2 lists the spectral windows used for the retrieval of each trace gas. Each was selected based on the fact that the gas(es) of interest possess significant (but unsaturated) IR absorption features within the window, and have limited interference from other species.

\subsubsection{Subtraction of ambient background spectra}

At the higher wavenumber (i.e. shorter wavelength) spectral regions used to retrieve $\mathrm{CO}_{2}, \mathrm{CO}, \mathrm{CH}_{4}$ and $\mathrm{CH}_{2} \mathrm{O}$ (2020$3100 \mathrm{~cm}^{-1}$; as listed in Table 2), the signal contribution from instrument self-emission and other ambient temperature sources is relatively minor (Müller et al., 1999). This is confirmed by the "ambient" spectrum shown in Fig. 4, which was collected without the silicon carbide glower IR source. However, the lower wavenumber $\left(900-940 \mathrm{~cm}^{-1}\right)$ region used to retrieve $\mathrm{NH}_{3}$ lies in the peak spectral emission region for ambient temperature bodies, and Fig. 4 confirms a substantial "ambient" signal at sub- $1500 \mathrm{~cm}^{-1}$ wavenumbers. This signal component needs to be removed from the measurement spectra prior to any trace gas retrieval, since it contains no information related to trace gas absorption. We therefore subtracted a relevant ambient SB spectrum from each measurement SB spectrum, making slight adjustments for MCT detector non-linearities according to Müller et al. (1999) to ensure the resultant "difference" spectrum showed zero signal in spectral regions expected to be fully opaque, such as the $668-670 \mathrm{~cm}^{-1} \mathrm{CO}_{2}$ absorption band (see Fig. 4 inset).

When this ambient spectral subtraction procedure is employed, the trace gas column amounts derived from the "corrected" measurement spectra increase compared to the nonsubtracted case. This can be inferred from the inset of Fig. 4, where the depth of the ammonia absorption feature is seen to remain unchanged after spectral subtraction, whilst the absolute magnitude of the spectral signal in the $\mathrm{NH}_{3}$ retrieval region (940-940 $\mathrm{cm}^{-1}$ ) has decreased significantly. This results in the forward model having to fit an increased optical thickness $(\tau)$ measure compared to the non-subtracted case, resulting in an increase in the derived $\mathrm{NH}_{3}$ column amount (assuming all other parameters remain fixed). However, whilst ammonia abundances retrieved using the 900$940 \mathrm{~cm}^{-1}$ spectral window more than double compared to the non-subtracted case, the relatively low ambient spectral signal in the higher wavenumber $\left(2020-3100 \mathrm{~cm}^{-1}\right)$ regions used to retrieve the carbonaceous compounds (c.f. Table 2 and Fig. 4) results in far less significant column amount increases, i.e. below $10 \%$. Furthermore, since the relatively similar increases seen in the carbonaceous compound column amounts retrieved in this region partly cancel out during ratio calculations, their emission ratios are even less affected by the spectral subtraction procedure (e.g. $\mathrm{ER}_{\mathrm{CO} / \mathrm{CO}_{2}}$ varies by $\sim 3 \%$ with and without spectral subtraction). Nevertheless, for consistency we employed the spectral subtraction procedure in all retrievals made here, and with a new ambient background spectrum recorded for each of the four experimental fires.

During the time that OP-FTIR measurements were being made at each fire, some changes in ambient environmental condition can be expected (e.g. air temperature, relative humidity). It was therefore important to gauge the degree to which such changes might affect the performance of the spectral subtraction procedure, which is based on use of a single representative "ambient" spectra recorded at each plot. This was examined by processing the same SB spectra from Fire 1 using two different ambient spectra, one taken somewhat before and one somewhat after the burn, with measurement times separated by $90 \mathrm{~min}$. Over this period, which is $3 \times$ longer than the $\sim 30$-min duration of the actual fire events, air temperature increased by $0.5^{\circ} \mathrm{C}$ and relatively humidity by $2 \%$, values representative of the variability seen over the course of the other fires. Corresponding changes are seen in the recorded ambient background spectra, for example a mean $10 \%$ signal change within the $900-940 \mathrm{~cm}^{-1}$ spectral region used to retrieve $\mathrm{NH}_{3}$. Two sets of corrected measurement spectra were then calculated for Fire 1, based on subtraction of each of the two ambient spectra. Passing these two sets of spectra through the full trace gas retrieval procedure showed that the retrieved $\mathrm{NH}_{3}$ column amounts do show some sensitivity to the ambient spectrum changes, varying by a mean of $7.3 \%(\sigma=1.2 \%)$. However, the carbonaceous gases (i.e. those retrieved using higher wavenumber regions; Table 2) showed little sensitivity to the ambient spectrum characteristics, as they are not very sensitive to the ambient background spectrum subtraction in general. Retrieved $\mathrm{CO}_{2}$ column amounts varied by a mean of $0.05 \%$ $(\sigma=0.003 \%)$, $\mathrm{CO}$ by $1.4 \%(\sigma=0.2 \%)$, and $\mathrm{ER}_{\mathrm{CO} / \mathrm{CO}_{2}}$ by less than $2.5 \%$.

\subsubsection{Performance of the trace gas retrieval procedure}

Figure 5a demonstrates the high quality of the match between our best-fit forward modelled SB spectra and the measured SB spectra, both prior to and during the fire (i.e. in "clean" and "smoke polluted" air). A full error analysis for the Burton (1998) retrieval approach can be found in Horrocks et al. (2001), who determined it to have an absolute accuracy of better than $5 \%$, with the uncertainty in the HITRAN spectral line parameters determined to be of a similar magnitude. Yokelson et al. (1997) calculated similar accuracies for MALT-based trace gas retrievals during closedpath FTIR studies of real smoke emissions, and recently Smith et al. (2011) showed similar accuracies when deriving concentrations of test carbonaceous gases contained in well-controlled cells, including at concentrations replicating 
the types of high pathlength amounts found in open biomass burning plumes.

Whilst only upwind air temperature, and not downwind smoke plume temperature, was recorded by the weather station during our KNP field experiment, plume temperature measurements made at subsequent open vegetation fires we have attended show that dilution and heat transfer typically cool the advected smoke to within a few Celsius of the ambient air temperature within a short distance of the combustion source (e.g. $\sim$ few tens of meters). Coupled with the relatively large area of the KNP burn plots, which meant that most measurement spectra were recorded with a long distance separating the dominant smoke source (i.e. the fire front) and the OP-FTIR optical path (Fig. 1), this resulted in the smoke plume temperature being close to ambient by the time it passed through the OP-FTIR optical path. Indeed, personnel could walk along the optical path and the fire breaks shown in Figs. 1 and 2 in full contact with the smoke without any significant thermal discomfort. Furthermore, tests allowing the a priori gas temperature to vary as part of the retrieval procedure did not result in increased temperatures providing an improved degree of fit, and the laboratory-based study of Smith et al. (2011) previously demonstrated that a $10^{\circ} \mathrm{C}$ error in assumed gas temperature typically results in a OP-FTIR retrieved carbonaceous gas column amount error of only a few percent. For these reasons, the spectral forward model used here to retrieve trace gas column abundances was initialized assuming fixed ambient atmospheric temperature conditions in both the plume and ambient air portions of the optical path (Fig. 1).

As an indication of the absolute accuracy of our trace gas retrieval procedure, we converted the pre-fire retrieved $\mathrm{CO}_{2}$ column amounts for Fire 1 to an equivalent mixing ratio measure, and compared this to the simultaneous measure provided by a newly-calibrated LICOR IR Gas Analyser. The mean ambient atmosphere $\mathrm{CO}_{2}$ mixing ratio derived from $15 \mathrm{~min}$ of pre-fire SB measurement spectra was $405 \pm 13 \mu \mathrm{mol} \mathrm{mol}^{-1}$ (mean \pm 1 s.d), which compares reasonably well to the $417 \pm 1 \mu \mathrm{mol} \mathrm{mol}{ }^{-1}$ measure provided by the LICOR. This degree of agreement is of the same order to that found previously by Yokelson et al. (1997) using MALT, and we also found reasonable pre-fire mixing ratios for all the other species examined in this work.

\subsection{Determination of derived trace gas plume metrics}

Column amounts (in molecules $\mathrm{cm}^{-2}$ ) represent the integration of the species volumetric abundance (molecules $\mathrm{cm}^{-3}$ ) along the optical pathlength $(l, \mathrm{~cm})$. The length of the optical path between the IR source and FTIR spectrometer was carefully measured, but the helicopter video record confirms that often only a fraction $(f)$ of the path was filled by plume (see example in Fig. 1, where the northernmost part of the optical path appears largely free of smoke). Therefore the trace gas column amounts retrieved from analysis of the SB spectra represent measurements from a mixture of ambient air and smoke in unknown relative amounts. Nevertheless, since for each species the optical pathlength $(l)$ is identical and constant over the period of a fire, the retrieved column amounts do represent the relative proportions of each trace gas present along the path. These column amounts can therefore be used to determine the emission ratios for each individual stage of each fire, along with their emissions factors and (modified) combustion efficiencies, as detailed below.

\subsubsection{Emission Ratios (ERs)}

Smoke emission ratios $\left[\mathrm{ER}_{\mathrm{x} / \mathrm{y}}\right]$ are commonly defined via the gradient of the linear best fit to the excess abundances of trace gas species $[\mathrm{x}]$ plotted against that of reference species [y] (Yokelson et al., 1999). $\mathrm{CO}_{2}$ is commonly the reference species for "flaming dominant" compounds, and CO for "smoldering dominant" (Andreae and Merlet, 2001). Where excess abundances are difficult to confidently calculate, for example in situations where "unpolluted" (e.g. non smokecontaminated) air is difficult to measure, Guyon et al. (2005) recommend using the gradient of the absolute trace gas mixing ratios rather than their excess amounts, an approach subsequently adopted by e.g. Keene et al. (2006). Furthermore, since in our OP-FTIR approach the smoke plume typically only partly fills the optical path, the number of molecules of species $[\mathrm{x}]$ and $[\mathrm{y}]$ present in the horizontal measurement column is an average of the amounts in the plume and ambient atmosphere, weighted by $f$, the unitless fraction of the optical path taken up by the pure plume, which can change greatly during the course of the measurement period as the plume builds and subsides (Horrocks, 2001):

$x=l f\left[X_{\mathrm{p}}\right]+l(1-f)\left[X_{\mathrm{a}}\right]$

$y=l f\left[Y_{\mathrm{p}}\right]+l(1-f)\left[Y_{\mathrm{a}}\right]$

where $\left[X_{\mathrm{p}}\right]$ and $\left[Y_{\mathrm{p}}\right]$ are, respectively, the mean molecular volumetric abundances of species $[\mathrm{x}]$ and $[\mathrm{y}]$ in the pure plume, and $\left[X_{\mathrm{a}}\right]$ and $\left[Y_{\mathrm{a}}\right]$ are the volumetric abundances of the same species in the pure ambient atmosphere (all expressed in units of molecules $\mathrm{cm}^{-3}$ ); and $[x]$ and $[y]$ are, respectively, the total column amounts of these species measured along the optical path (in units of molecules $\mathrm{cm}^{-2}$ ); $l$ is the pathlength (here expressed in $\mathrm{cm}$ ) and $f$ the unitless fraction of the optical path taken up by the pure plume.

Subtracting pre-fire "ambient" abundances from those derived from the during-fire measurements in order to calculate the excess trace gas amounts is therefore not fully correct, since only fraction (1- $f$ ) of the optical path contains "clean" air. Fortunately Eqs. (1) and (2) can be combined to remove dependence on the unknown and highly variable $f$ :

$y=\left(\frac{Y_{\mathrm{p}}-Y_{\mathrm{a}}}{X_{\mathrm{p}}-X_{\mathrm{a}}}\right) x-l\left[X_{\mathrm{a}}\left(\frac{Y_{\mathrm{p}}-Y_{\mathrm{a}}}{X_{\mathrm{p}}-X_{\mathrm{a}}}\right)-Y_{\mathrm{a}}\right]$

Equation (3) is effectively the equation of a straight line $(\mathrm{y}=m \mathrm{x}+\mathrm{c})$ obtained when the column amount of species $[\mathrm{y}]$ 
is plotted against that of species $[\mathrm{x}]$, where the gradient $(\mathrm{m})$ is a function of the relative abundance of the two species in the "pure" plume and "pure" atmosphere:

$m=\left(\frac{Y_{\mathrm{p}}-Y_{\mathrm{a}}}{X_{\mathrm{p}}-X_{\mathrm{a}}}\right)$

Under the assumption that volumetric abundances of the target species in the pure "unmixed" plume are much greater than those in the pure ambient atmosphere (i.e. $Y_{\mathrm{p}} \gg Y_{\mathrm{a}}$ and $X_{\mathrm{p}} \gg X_{\mathrm{a}}$ ) then the value of $m$ approaches that of the molar emissions ratio of the pure plume (i.e. $\mathrm{ER}_{\mathrm{x} / \mathrm{y}}=Y_{\mathrm{p}} / X_{\mathrm{p}}$ ). Gases having both high in-plume abundances $\left(\mathrm{CO}_{2} \sim 90 \%\right.$ and $\mathrm{CO} \sim 6 \%$ on a dry air basis according to Andreae and Merlet, 2001) and relatively low in-plume abundances $\left(\mathrm{CH}_{4} \sim 0.3 \%, \mathrm{CH}_{2} \mathrm{O} \sim 0.09 \%, \mathrm{NH}_{3} \sim 0.04 \%\right)$ exist in concentrations orders of magnitude greater than in the ambient atmosphere. The maximum error introduced by the use of Eq. (4) to approximate $\mathrm{ER}_{\mathrm{x} / \mathrm{y}}$ will occur for combinations of gases whose volumetric abundance in the "pure" plume is closest to that in the ambient atmosphere, in our case $\mathrm{CO}_{2}$ ( $\sim 2500 \times$ higher volumetric abundance in the plume than in the dry atmosphere $)$ and $\mathrm{CH}_{4}(\sim 1800 \times$ higher in the plume than in the dry atmosphere). Even in this "worst" case, the error introduced by use of the gradient $[\mathrm{m}]$ to approximate $\mathrm{ER}_{\mathrm{CO} 2 / \mathrm{CH} 4}$ remains below $0.05 \%$, including accounting for the fact that the volumetric abundance of water vapour in the plume is greater than in the ambient atmosphere. Hence, as with volcanic plumes (e.g. Sawyer et al., 2008), we can confidently proceed to calculate emission ratios directly from the retrieved trace gas column amounts, with no need to try to separate the "ambient atmosphere" and "plume" components, nor to calculate excess abundances.

The $\mathrm{ER}_{\mathrm{x} / \mathrm{y}}$ of two trace gas species can vary substantially between different combustion processes, resulting in divergent gradients in the $[\mathrm{x}]$ vs. [y] column amount scatter plots used to derived the emission ratio measure. This is often less apparent in large scale airborne measurements from open burning, where the smoke sampled is often a mixture generated by multiple processes occurring simultaneously, and is perhaps more evident in data from ground-based in situ sampling of open burning or small-scale laboratory measurements, that are more likely to capture examples of "single process" combustion (e.g. see example flaming and smouldering $\mathrm{CO}$ vs. $\mathrm{CO}_{2}$ scatter plots derived from laboratory combustion experiments in Fernández-Gómez et al., 2010). Process-specific emission ratios are often calculated from these type of measurements, based on trace gas records collected during only the time period where that specific process (e.g. flaming combustion) was noted to occurr, or where the measurements have been separated out into those representing different phases based on e.g. their (modified) combustion efficiency characteristics (e.g. Yokelson et al., 1997). To calculate "fire averaged" emission ratios from phase-specific $\mathrm{ER}_{\mathrm{x} / \mathrm{y}}$ measures, the entire amount of species [x] and [y] released in each phase can be measured and ratioed, which is achievable in laboratory studies but impossible for most field setups. Alternatively the weighted average of the instantaneous or phase-specific $\mathrm{ER}_{\mathrm{x} / \mathrm{y}}$ measures can be calculated, based on the amount of fuel consumed in the relevant time interval. Such fuel consumption data are again relatively easily obtained during laboratory-scale measurements, but are usually unavailable in field situations. As with airborne plume sampling, the long pathlength OP-FTIR measurements of the current study provide spatially integrated measurements of the smoke generated by multiple combustion processing occurring simultaneously across the plot, and we therefore do not sample specific combustion processes separately. Nevertheless, we do generate separate $\mathrm{ER}_{\mathrm{x} / \mathrm{y}}$ measures for the three separate stages of each fire (backfire, headfire, RSC), as we wish to determine whether the various trace gas emissions ratios and emissions factors vary between stages. It is impossible to obtain a direct measurement of the fuel consumed in each stage, but we use the measurement of Fire Radiative Energy (FRE) released in each stage as an indicator of the relative amount of fuel burned. FRE is derived from temporal integration of the helicopter-born FRP observations, and is linearly proportional to fuel consumption irrespective of whether the fire activity is flaming or smouldering, providing the emitter temperature exceeds $\sim 700 \mathrm{~K}$ (Wooster et al., 2003, 2005).

It should be noted that whilst the airborne observations were used to derive an FRE measure that integrated the thermal emission signal of the combustion occurring across the entire plot, the OP-FTIR measurements did not always encompass the full width of the plume due to the optical path not extending along the complete $\sim 380 \mathrm{~m}$ downwind plot border, and so some of the ground-level plume sometimes remained unsampled. Nevertheless, careful inspection of the aerial video record suggests that the optical paths of our OPFTIR deployments were appropriate to effectively sample large parts of the plume from each stage of each fire. Thus, when calculating "fire averaged" emission ratios via weighting of the individual stage ERs by that stages recorded FRE value, we rely on our spatially integrated open path trace gas measurements being representative of the entire plume width.

\subsubsection{Emission Factors (EFs)}

We calculate the emissions factor for species $[\mathrm{x}]$ using the carbon mass balance method of Ward and Radke (1993). This assumes that the carbon content of the fuel is released into the atmosphere as measurable carbon compounds, allowing the emissions factor for each species to be calculated from a series of emission ratios using a total carbon balance (assuming we know the mass fraction of carbon within the vegetation, e.g. Yokelson et al., 1999; Goode et al. 2000; Sinha et al., 2003):

$E F_{\mathrm{x}}=F_{\mathrm{c}} 1000 \frac{M M_{\mathrm{x}}}{M M_{\text {carbon }}} \frac{C_{\mathrm{x}}}{C_{T}}$ 
Where $\mathrm{EF}_{\mathrm{x}}$ is the emissions factor for species $x\left(\mathrm{~g} \mathrm{~kg}^{-1}\right)$, $F_{\mathrm{c}}$ is the mass fraction of carbon in the fuel (taken here as $0.5 \pm 0.05$ as with the majority of other studies; Ward et al., 1996), $M M$ is the molecular mass of species $x(\mathrm{~g})$, $1000 \mathrm{~g} \mathrm{~kg}^{-1}$ is a unit conversion factor, $M M_{\text {carbon }}$ is the molecular mass of carbon $(12 \mathrm{~g})$, and $C_{\mathrm{x}} / C_{T}$ is the ratio of the number of moles of species $x$ in the plume divided by the total number of moles of carbon, calculated as:

$$
\frac{C_{\mathrm{x}}}{C_{T}}=\frac{\mathrm{ER}_{\mathrm{x} / \mathrm{CO}_{2}}}{\sum_{j=1}^{n}\left(\mathrm{NC}_{j} \mathrm{ER}_{\left.j / \mathrm{CO}_{2}\right)}\right.}
$$

Where $\mathrm{ER}_{\mathrm{x}} / \mathrm{CO}_{2}$ is the emission ratio of species $\mathrm{x}$ to $\mathrm{CO}_{2}$, $\mathrm{NC}_{j}$ is the number of carbon atoms in compound $j$, and the sum is over all carbonaceous species including $\mathrm{CO}_{2}$.

As is typical in past studies, not all carbon containing species were actually quantified in our analysis. However, Delmas et al. (1995) and Keene et al. (2006) show that $\mathrm{CO}_{2}$, $\mathrm{CO}$ and $\mathrm{CH}_{4}$ account for the vast majority of the total carbon flux from open biomass burning, a median of around $99 \%$ in the case of southern African savannah fires. The majority of the remaining carbon is emitted as non-methane organic compounds and aerosols (Akagi et al., 2010). The four carbonaceous gases we do measure $\left(\mathrm{CO}_{2}, \mathrm{CO}, \mathrm{CH}_{4}\right.$ and $\mathrm{CH}_{2} \mathrm{O}$ ) therefore clearly represent almost the total mass of carbon released, and unmeasured trace gases and particulates are ignored in our application of Equations 5 and 6. Such a simplification is common during application of the carbon mass balance approach, and inflates the derived EFs by a few percent at most (Yokelson et al., 1999; Andreae and Merlet, 2001; Goode et al., 2000).

\subsubsection{Modified Combustion Efficiency (MCE)}

The combustion efficiency (CE) of a fire is the ratio of $\mathrm{CO}_{2}$ emitted to total carbon emitted. However, usually not all carbonaceous species are measured and so the combustion efficiency (CE) cannot be calculated. Instead a modified version (the MCE) is considered, being the molar ratio of carbon emitted in the form of $\mathrm{CO}_{2}$ to that emitted as $\mathrm{CO}$ and $\mathrm{CO}_{2}$, which approximates the true $\mathrm{CE}$ as these two gases represent the vast majority of emitted carbon (Ward and Radke, 1993):

$$
\mathrm{MCE}=\frac{\Delta \mathrm{CO}_{2}}{\left(\Delta \mathrm{CO}_{2}+\Delta \mathrm{CO}\right)}
$$

where $\Delta \mathrm{CO}_{2}$ and $\Delta \mathrm{CO}$ indicate the excess mixing ratio of those species (Ward and Radke, 1993).

Linear relationships between species $\mathrm{EF}_{\mathrm{x}}$ and MCE were used by Goode et al. (2000) to propose a mechanism to estimate the emission factors of unmeasured species in cases where at least $\mathrm{CO}$ and $\mathrm{CO}_{2}$ measures are available, thus highlighting the potential importance of the MCE measure. Our data in theory allow the MCE (and indeed also ERs) to be derived at a very high temporal resolution (i.e. from each individual SB spectrum), though for this it is necessary to base the calculation on excess trace gas abundances rather than total column amounts. The MCE for each fire stage can be also be calculated via the relevant $\mathrm{ER}_{\mathrm{co} / \mathrm{co}_{2}}$ measure using:

$\mathrm{MCE}=\frac{1}{\left(1+\mathrm{ER}_{\left.\mathrm{CO} / \mathrm{CO}_{2}\right)}\right.}$

In this work we simply use the MCE measures as an aid to the interpretation of fire behaviour, rather than to derive other quantities or to separate the measurements into those representative of individual combustion processes or stages.

\section{Results and discussion}

Figure 6 shows the time-series of trace gas horizontal column amounts, FRP, MCE and remotely sensed fire IR brightness temperature for the first of the 7 ha experimental burns (Fire 1). Records from the ignition team and study of the optical and thermal video records confirm that the initial, narrower pulse of trace gas and FRP data seen in Fig. 6 (peaking at $\sim 17 \mathrm{~min}$ ) result from the backfire activity alone, whilst the later, wider pulse (peaking at $\sim 23 \mathrm{~min}$ ) is dominated by the subsequently ignited headfire. The headfire of Fire 1 was recorded as having extinguished at the downwind end of the plot 39 min after the start of the record shown in Fig. 6, though some FRP and substantial smoke continued to be released for many minutes thereafter and we take this as our RSC sample. Somewhat similar patterns are seen in the data for each of the four fires conducted, though no FRP observations are available for Fire 4 due to difficulties with the thermal imager.

The evolution of each of the trace gas time series shown in Fig. 6 is broadly similar for each species, generally reflecting gross variations in the amount of smoke being produced by the fire and being advected into the OP-FTIR optical path. The effect of relative changes in the various combustion processes occurring within the plot is superimposed onto this general pattern, for example with a proportionally higher amount of $\mathrm{CO}$ compared to $\mathrm{CO}_{2}$ measured during periods where smouldering activity is more widespread (e.g. resulting in a reduced MCE, for example in the RSC stage). The shape of the FRP timeseries also broadly matches that of the trace gases, a pattern seen previously in the results of small-scale laboratory combustion experiments reported in Freeborn et al. (2008). We do see a small temporal shift between the timing of the FRP and trace gas peaks, since whilst the overhead AGMEA-550 instantaneously registers the fire's thermal radiation release, the smoke takes time to travel from the main source location (i.e. the fire front) into the OP-FTIR optical path. This small temporal offset has little impact on our analysis however, since the thermal camera and trace gas time series are never compared on an instantaneous basis, apart from in discussion of MCE (Sect. 4.4). The peaks in the trace gas and FRP records do, however, show different relative magnitudes over the fires lifetime, in 
Table 3. Molar emission ratios and associated uncertainties for compound $\mathrm{x}$ with respect to both $\mathrm{CO}\left(\mathrm{ER}_{\mathrm{x} / \mathrm{CO}}\right)$ and $\mathrm{CO}_{2}\left(\mathrm{ER}_{\mathrm{x} / \mathrm{CO}_{2}}\right)$, reported for the backfire, headfire and residual smouldering combustion (RSC) stages of Fires 1 to 4 and calculated using methods described in Sect. 4.2. Poorly constrained ERs [those with $r^{2}$ lower than 0.4] are not reported here. "Fire averaged" ERs are calculated using stagespecific ERs weighted by the FRE-determined proportion of fuel burned in each stage (apart from for Fire 4 where FRE data are unavailable). Uncertain ERs for the RSC stage do not prevent calculation of fire averaged values, since an insignificant amount of fuel is burned in this fire stage (Table 1). Final three rows show the mean $\mathrm{ER}_{\mathrm{x} / \mathrm{y}} \pm 1 \sigma$ calculated from the available fire averages, results for the same study area derived via aircraft sampling of lofted emissions by Sinha et al. (2003), and results from the study of Bertschi et al. (2003) where the ER's for a group of tropical wooded savannah logs from Zambia were measured whilst undergoing residual smouldering combustion RSC.

\begin{tabular}{|c|c|c|c|c|c|c|c|c|}
\hline \multirow[b]{2}{*}{ Fire } & \multirow[b]{2}{*}{ Fire Stage } & \multirow{2}{*}{$\begin{array}{l}\mathrm{CO} \\
\mathrm{ER}_{\mathrm{x} / \mathrm{CO}_{2}} \\
(\times 100)\end{array}$} & \multicolumn{2}{|c|}{$\mathrm{CH}_{4}$} & \multicolumn{2}{|c|}{$\mathrm{CH}_{2} \mathrm{O}$} & \multicolumn{2}{|c|}{$\mathrm{NH}_{3}$} \\
\hline & & & $\begin{array}{l}\mathrm{ER}_{\mathrm{x} / \mathrm{CO}_{2}} \\
(\times 1000)\end{array}$ & $\begin{array}{l}\mathrm{ER}_{\mathrm{x}} / \mathrm{CO} \\
(\times 100)\end{array}$ & $\begin{array}{l}\mathrm{ER}_{\mathrm{x} / \mathrm{CO}_{2}} \\
(\times 1000)\end{array}$ & $\begin{array}{l}\mathrm{ER}_{\mathrm{x} / \mathrm{CO}} \\
(\times 100)\end{array}$ & $\begin{array}{l}\mathrm{ER}_{\mathrm{x}} / \mathrm{CO}_{2} \\
(\times 1000)\end{array}$ & $\begin{array}{l}\mathrm{ER}_{\mathrm{x}} / \mathrm{CO} \\
(\times 100)\end{array}$ \\
\hline 1 & Head & $10.1 \pm 0.6$ & $4.6 \pm 0.5$ & $4.9 \pm 0.2$ & $2.2 \pm 0.1$ & $2.2 \pm 0.1$ & $2.1 \pm 0.3$ & $2.3 \pm 0.1$ \\
\hline 1 & Back & $11.4 \pm 0.5$ & $6.0 \pm 0.4$ & $5.2 \pm 0.4$ & $3.2 \pm 0.4$ & $2.8 \pm 0.3$ & $1.8 \pm 0.2$ & $1.5 \pm 0.2$ \\
\hline \multirow[t]{2}{*}{1} & RSC & $9.6 \pm 1.3$ & $6.7 \pm 1.2$ & $7.4 \pm 0.4$ & $1.7 \pm 0.3$ & $1.8 \pm 0.2$ & $3.2 \pm 0.5$ & $3.5 \pm 0.1$ \\
\hline & Fire 1 Averaged & $10.3 \pm 0.6$ & $4.8 \pm 0.5$ & $5.0 \pm 0.2$ & $2.3 \pm 0.2$ & $2.3 \pm 0.1$ & $2.1 \pm 0.3$ & $2.2 \pm 0.1$ \\
\hline 2 & Head & $6.2 \pm 0.6$ & $2.4 \pm 0.4$ & $3.9 \pm 0.5$ & $1.2 \pm 0.2$ & $2.0 \pm 0.2$ & - & $1.4 \pm 0.2$ \\
\hline 2 & Back & $5.9 \pm 0.5$ & $1.9 \pm 0.2$ & $3.2 \pm 0.3$ & $1.5 \pm 0.1$ & $2.6 \pm 0.1$ & $0.4 \pm 0.1$ & $0.8 \pm 0.1$ \\
\hline \multirow[t]{2}{*}{2} & RSC & $6.1 \pm 0.5$ & $3.1 \pm 0.3$ & $4.5 \pm 0.4$ & $1.3 \pm 0.1$ & $2.0 \pm 0.2$ & $0.9 \pm 0.1$ & $1.7 \pm 0.2$ \\
\hline & Fire 2 Averaged & $6.2 \pm 0.6$ & $2.4 \pm 0.4$ & $3.8 \pm 0.5$ & $1.2 \pm 0.2$ & $2.0 \pm 0.2$ & - & $1.4 \pm 0.2$ \\
\hline 3 & Head & $12.3 \pm 3.2$ & $5.4 \pm 1.8$ & $4.8 \pm 0.4$ & $2.7 \pm 0.7$ & $2.2 \pm 0.1$ & $2.4 \pm .1 .0$ & $2.2 \pm 0.3$ \\
\hline 3 & Back & $7.4 \pm 0.7$ & $2.2 \pm 0.4$ & $3.2 \pm 0.3$ & $1.5 \pm 0.2$ & $2.0 \pm 0.1$ & $0.8 \pm 0.2$ & $1.2 \pm 0.2$ \\
\hline 3 & RSC & $17.4 \pm 0.2$ & $14.1 \pm 0.2$ & $8.0 \pm 0.4$ & $3.1 \pm 0.4$ & $1.7 \pm 0.1$ & $5.3 \pm 0.9$ & $3.1 \pm 0.2$ \\
\hline & Fire 3 Averaged & $12.3 \pm 0.3$ & $5.6 \pm 1.7$ & $4.9 \pm 0.4$ & $2.7 \pm 0.7$ & $2.2 \pm 0.1$ & $2.4 \pm 1.0$ & $2.2 \pm 0.3$ \\
\hline 4 & Head & $7.9 \pm 1.6$ & - & $4.7 \pm 0.7$ & $1.9 \pm 0.3$ & $2.3 \pm 0.1$ & - & $1.9 \pm 0.2$ \\
\hline 4 & Back & $6.9 \pm 0.4$ & $2.1 \pm 0.2$ & $3.2 \pm 0.2$ & $1.8 \pm 0.1$ & $2.6 \pm 0.8$ & $0.9 \pm 0.1$ & $1.5 \pm 0.1$ \\
\hline \multirow[t]{2}{*}{4} & $\mathrm{RSC}$ & $22.4 \pm 1.4$ & $13.1 \pm 1.1$ & $6.0 \pm 0.2$ & $4.2 \pm 0.3$ & $1.9 \pm 0.1$ & $6.5 \pm 0.5$ & $3.0 \pm 0.1$ \\
\hline & $\begin{array}{l}\text { "Fire Averaged" mean } \\
( \pm \sigma) \text { (not inc. Fire } 4)\end{array}$ & $9.6 \pm 3.1$ & $4.3 \pm 1.7$ & $4.6 \pm 0.7$ & $2.1 \pm 0.8$ & $2.2 \pm 0.2$ & $2.3 \pm 0.2$ & $1.9 \pm 0.5$ \\
\hline Sinha et al. (2003) & $\begin{array}{l}\text { Aircraft Sampling } \\
\text { (lofted emissions) }\end{array}$ & $7.2 \pm 0.9$ & - & $3.9 \pm 0.3$ & - & $1.5 \pm 0.4$ & - & $0.7 \pm 0.5$ \\
\hline Bertschi et al. (2003) & $\begin{array}{l}\text { Zambian woody fuel } \\
\text { (RSC emissions) }\end{array}$ & 17.1 & - & 25.6 & - & 2.05 & - & 1.99 \\
\hline Christian et al. (2007) & $\begin{array}{l}\text { Brazil Smouldering } \\
\operatorname{logs}(\text { RSC emissions) }\end{array}$ & $27.5 \pm 9.3$ & - & $14.3 \pm 8.6$ & - & $0.80 \pm 0.46$ & - & $1.28 \pm 1.1$ \\
\hline
\end{tabular}

part because whilst the thermal camera records radiation being emitted from the entire plot, the proportion of the whole plume being sampled by the OP-FTIR varies somewhat over the fire's lifetime (see Sect. 3.5). Nevertheless, the strong degree of temporal similarity in the trace gas and FRP time series is interpreted to mostly represent variations in active fire coverage, since as the ignited fire front starts to move across the plot it grows in spatial extent, burning more fuel per unit time and thus increasing both the "plot integrated" FRP measure and the rate of trace gas production. After the active fire front reaches its maximum spatial extent (e.g. parts of it reach the plot boundary and/or previously burned areas), its ability to access new areas of fuel begins to decrease, and so the FRP and trace gas column amounts both start to fall. Conversely, if the fire front reaches an area of the plot with a locally higher fuel load, then (if all other factors remain constant) both the FRP and trace gas time-series show a local increase. In contrast to this short-timescale variability, the MCE data show a slower trend since the ratio-based MCE calculation removes dependence on total trace gas column amount. The MCE data do not therefore appear strongly influenced by the fire fronts spatial extent, for example with no peak in MCE corresponding to that in FRP seen during the headfire stage. Instead the MCE measure provides an indication of the relative dominance of smouldering and flaming emissions within the smoke being sampled (Reid et al., 2005).

\subsection{Emission ratios}

Molar emissions ratios were determined using the methods described in Sect. 3.5. As an example, Fig. 7 (top row) shows the $\mathrm{CO}$ and $\mathrm{CO}_{2}$ column amounts plotted against one another for the headfire, backfire and RSC stage of Fire 1, with the gradient of the least squares linear best-fit taken as the emis-

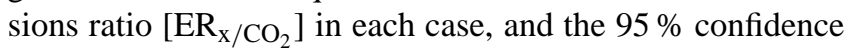
limits on the gradient providing an estimate of the $\mathrm{ER}_{\mathrm{x} / \mathrm{CO} 2}$ uncertainty. Comparison of these ratios to those calculated via first converting the FTIR-determined column amounts to the equivalent excess molar abundances (as per Sinha et al., 

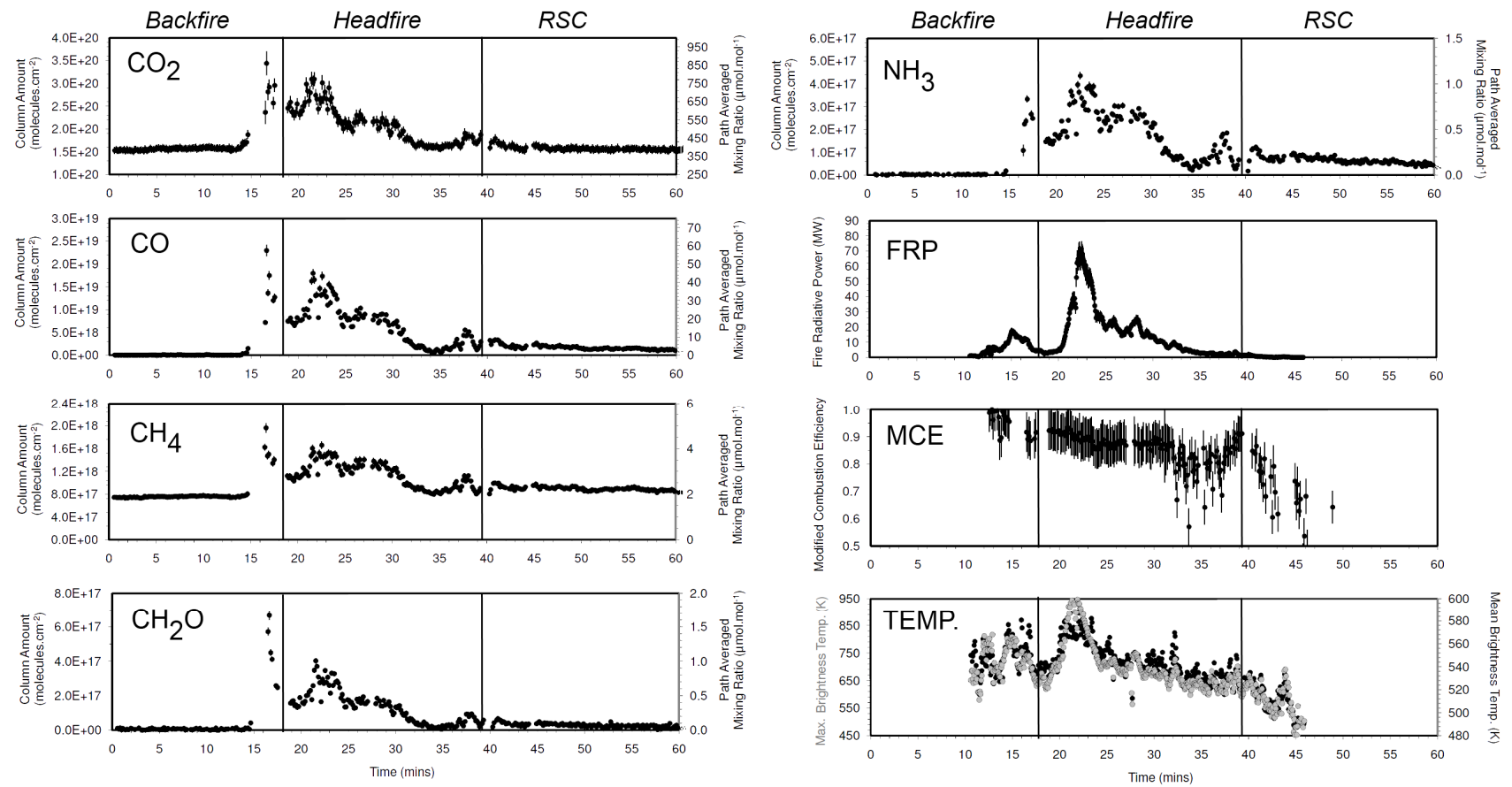

Fig. 6. Time-series of trace gas column amounts, Fire Radiative Power, Modified Combustion Efficiency (MCE) and fire temperature for Fire 1 (Figs. 1, 2 and 3 and Table 1). Trace gas amounts are expressed as path-integrated column amounts (molecules $\mathrm{cm}^{-2}$ ), with the equivalent path averaged mixing ratio shown on the r.h.s. y-axis. After the 14:01 h ignition time (time $>10$ min on this plot) these mixing ratios represent a weighted average of the pure plume and ambient air abundances (See Sect. 3.5). Error bars for the trace gas retrievals are calculated from the residuals of the best-fit forward modeled spectra (Horrocks et al., 2001), whilst those for FRP are calculated according to Wooster et al. (2005). The three stages of the fire, defined in Sect. 3.1, are separated by the vertical bars.

2003) confirmed differences of less than $1 \%$. Emissions ratios of each targeted species to both $\mathrm{CO}_{2}$ and $\mathrm{CO}$ were assessed in this way, and Fig. 7 (lower row) shows, for example, the scatterplots used to derive $\mathrm{ER}_{\mathrm{x} / \mathrm{CO}}$ for the headfire stage of Fire 1 for each of the additional three species investigated herein. Table 3 details the emissions ratio results for each stage of each fire, and these are plotted as a histogram in Fig. 8 to aid interpretation and intercomparison. Following Sinha et al. (2003) we used the strength of the coefficient of determination $\left(r^{2}\right)$ between the abundance of a particular gas species and that of $\mathrm{CO}$ or $\mathrm{CO}_{2}$ to confirm the emissions ratio for that gas as well determined. Most had $r^{2}>0.7$, and those species for which the coefficient of determination fell below 0.4 are assumed to be poorly determined and are not reported. As is commonly the case (Andreae and Merlet, 2001), for most gases there was usually a somewhat better correlation between its abundance and that of $\mathrm{CO}$ rather than $\mathrm{CO}_{2}$ [expected due to their common preferential production during smouldering activity], but the $\mathrm{ER}_{\mathrm{x} / \mathrm{CO}_{2}}$ ratio was nevertheless derived since it is required for later derivation of emissions factors via the carbon mass balance method (Eqs. 5 and 6).
Overall, our results confirm that emission ratios to $\mathrm{CO}_{2}$ (i.e. $\mathrm{ER}_{\mathrm{x} / \mathrm{CO}_{2}}$ ) for $\mathrm{CO}$ and $\mathrm{CH}_{4}$ and $\mathrm{NH}_{3}$ are often higher during the RSC stage as compared to the flaming stages, whereas those of $\mathrm{CH}_{2} \mathrm{O}$ are less so. Emission ratios to $\mathrm{CO}$ are also in general somewhat higher for $\mathrm{CH}_{4}$ and $\mathrm{NH}_{3}$ during the RSC stage than during the flaming stages, but the reverse is true for $\mathrm{CH}_{2} \mathrm{O}$. Results for Fire 1 appear to follow these trends less clearly than those of the other fires, for reasons discussed below. The contrasting relationships shown for formaldehyde are interpreted to result from its higher production during pyrolysis (Yokelson et al., 1996), thus providing more limited opportunities for its creation during the RSC stage where flaming activity is very significantly reduced compared to the headfire or backfire stages.

Lacaux et al. (1996) provide one of the only prior studies to compare savannah headfire and backfire ERs, measured using a $\mathrm{CO}$ and $\mathrm{CO}_{2}$ analyser deployed at fires including those conducted on the KNP plots. The arithmetic mean of the headfire $\mathrm{ER}_{\mathrm{CO} / \mathrm{CO}_{2}}$ values determined for different savannah fires by Lacaux et al. (1996) varied over a $(4.0-12.8) \times 10^{-2}$ range, rather similar to the (6.2-12.3) $\times 10^{-2}$ range found in our study. However, when Lacaux et 


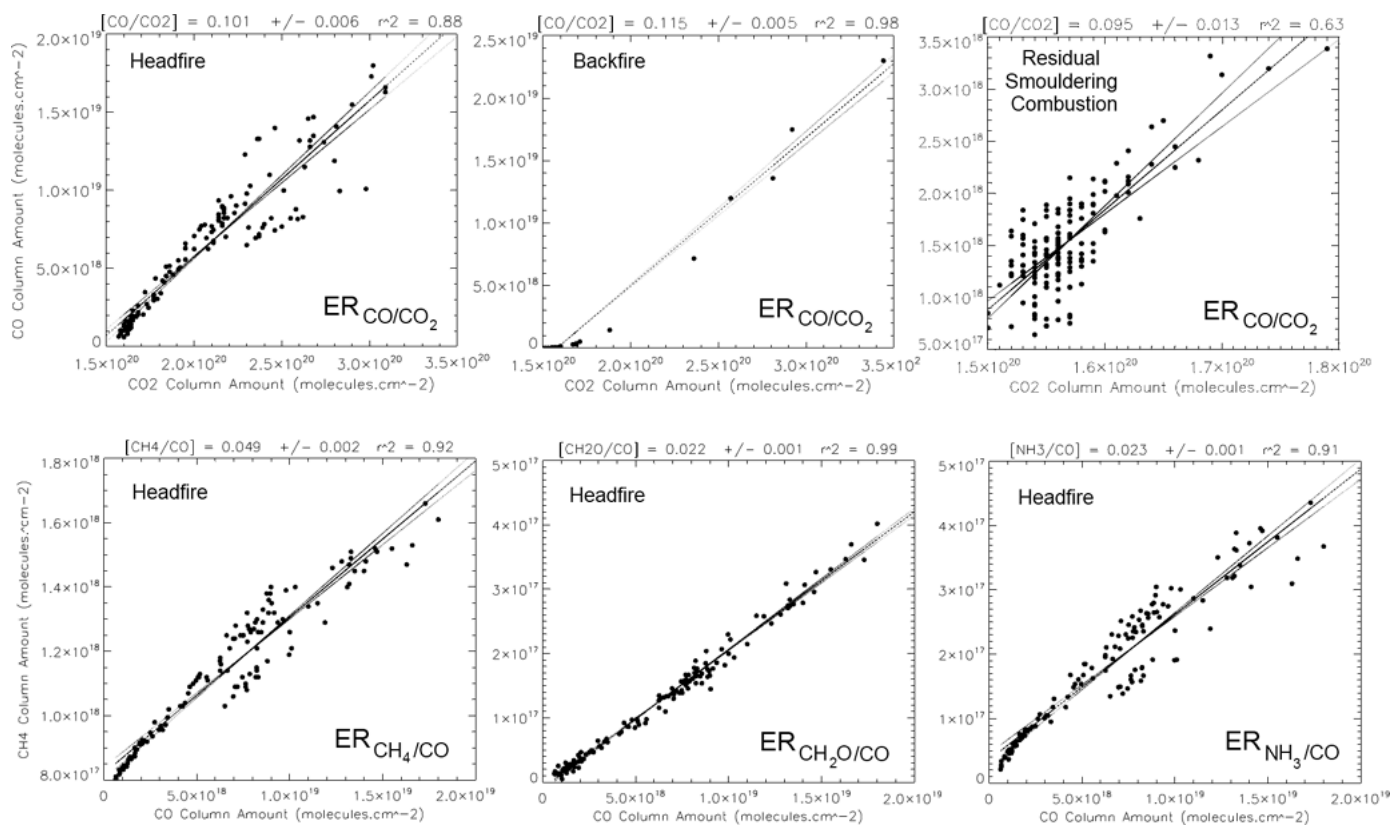

Fig. 7. Example 2-D scatterplots of the measured trace gas column amounts used to calculate emissions ratios. Data are from Fire 1, whose time-series measurements are shown in Fig. 6. Top row shows the $\mathrm{CO}$ vs. $\mathrm{CO}_{2}$ data for the backfire, headfire and residual smouldering combustion stages of this fire. Bottom row shows the $\mathrm{CH}_{4}$ vs. $\mathrm{CO} ; \mathrm{CH}_{2} \mathrm{O}$ vs. $\mathrm{CO}$ and $\mathrm{NH}_{3}$ vs. $\mathrm{CO}$ data for the headfire stage only. The slope of the least squares linear best fit to these data (shown, along with its uncertainty) is used to derive the relevant emission ratio $\left(\mathrm{ER}_{\mathrm{x} / \mathrm{y}}\right)$, whose value is shown above the relevant plot. Note the different axes scales required to accommodate the varying column amounts measured during the various fires stages.

al. (1996) weighted their separate ER measures for the headfire flaming and smoking zones by an estimate of the amount of fuel believed to have been consumed in each (an assumed ratio of 9:1 respectively) they obtained lower $\mathrm{ER}_{\mathrm{CO} / \mathrm{CO}_{2}}$ values of (3.0-5.8) $\times 10^{-2}$. Lacaux et al. (1996) also quote a backfire $\mathrm{ER}_{\mathrm{CO} / \mathrm{CO} 2}$ range of (3.4-7.0) $\times 10^{-2}$, which is again lower than the $(5.9-11.4) \times 10^{-2}$ range found in our study. Lacaux et al. (1996) concluded that headfire and backfire $\mathrm{ER}_{\mathrm{CO} / \mathrm{CO}_{2}}$ are relatively similar, a finding that results for most of the fires in our study agrees with. However, unlike Cofer et al. (1996) who suggest $\mathrm{ER}_{\mathrm{CO} / \mathrm{CO}_{2}}$ of flaming and smouldering combustion for KNP fires to be within a few percent of one another, our results suggest substantial differences can occur. We find smouldering stage $\mathrm{ER}_{\mathrm{CO} / \mathrm{CO}_{2}}$ to vary over a $(9.5-22.4) \times 10^{-2}$ range, similar to the $(12.1-$ 20.8) $\times 10^{-2}$ range found by Lacaux et al. (1996), and certainly more different to the flaming stage $\mathrm{ER} \mathrm{CO} / \mathrm{CO}_{2}$ than suggested by Cofer et al. (1996).

Our results for Fire 1 depart somewhat from those of the other fires, in particular in having a $\mathrm{ER}_{\mathrm{CO} / \mathrm{CO}_{2}}$ that is similar for all three fire stages (headfire, backfire and RSC), and with values a little higher than for most of the other headfires and backfires studied. Though the reason remains uncertain, a possible cause may be the large amount of (primarily elephant) dung present in the interior of the Fire 1 burn plot, which was not obviously present on any other plot and which continued to burn for a long time after passage of the flaming front (Fig. 2c), thus contributing to emissions in all three stages of this fire. We measured the characteristics of the dung piles as consisting of 3 or 4 pellets, each weighing around $380 \mathrm{~g}$, and with piles spaced $\sim 5-10 \mathrm{~m}$ apart (Fig. 2c). The exact locations and combustion completeness of the dung was not recorded, but coverage was extensive and calculations suggest it may have added $10-50 \mathrm{~g} \mathrm{~m}^{-2}$ to the fuel consumption of Fire 1 (estimated without this contribution to be $101 \pm 82 \mathrm{~g} \mathrm{~m}^{-2}$; Table 1). Crockett and Engle (1999) confirm that burning of (North American Bison) dung ignited by grassfires can continue for very substantial periods after the flaming front has passed, and that the combustion characteristics of this fuel are very different to those of the underlying vegetation. Scholes et al. (1996) and Shea et al. (1996) both previously report dung burning at some of the KNP burn plots, and Keene et al. (2006) report that southern African (cow) dung has an $\mathrm{EF}_{\mathrm{CO}}$ around twice that of burning grasses, and an $\mathrm{EFCO}_{2}$ around half that of burning grass, values confirmed by Christian et al. (2007). Somewhat similar figures are reported in Akagi et al. (2011). Therefore, when averaged over the full combustion process, the $\mathrm{ER}_{\mathrm{CO} / \mathrm{CO}_{2}}$ of dung is close to four times that of grass, but some of the dung also continued flaming in the RSC stage of Fire 1, whereas the other fuels were mostly smouldering, so it seems possible that dung burning may have increased the 

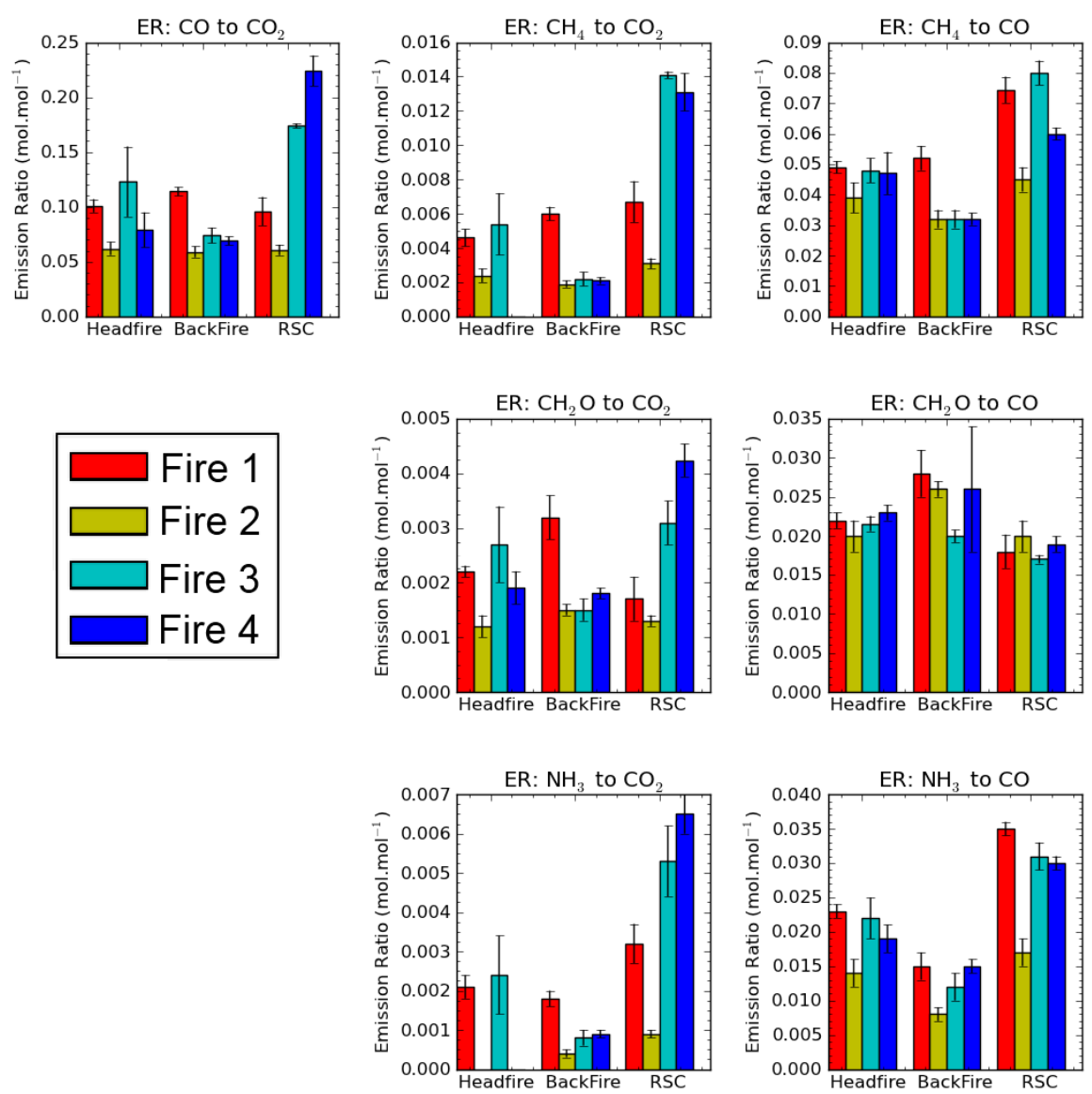

Fig. 8. Emission ratios $\left[\mathrm{ER}_{\mathrm{x} / \mathrm{y}}\right]$ for $\mathrm{CO}_{2}, \mathrm{CO}, \mathrm{CH}_{2} \mathrm{O}$ and $\mathrm{NH}_{3}$ for the backfire, headfire and residual smouldering combustion (RSC) stages of Fires 1, 2, 3 and 4 (see Table 1 for fire details). ERs to both $\mathrm{CO}$ and $\mathrm{CO}_{2}$ are shown, and missing values indicate cases where the derived $\mathrm{ER}_{\mathrm{x} / \mathrm{y}}$ was poorly constrained based on a low coefficient of determination $\left(r^{2}\right)$ between the two relevant trace gas column amounts. This may be due in some cases to short periods where the plume blew outside of the optical path, and in others to instances where the relationship between the two trace gas column amounts is not well described by a linear fit. ER uncertainties are given by the error bars, derived from the $95 \%$ confidence limits in the slope of the least squares linear best fit to the trace gas column amounts (see Fig. 7).

$\mathrm{ER}_{\mathrm{CO} / \mathrm{CO}_{2}}$ in the headfire and backfire stages, and perhaps decreased it during the RSC stage. This, coupled with the extra fuel load provided by dung (of between 10 and $50 \%$ ), seems a possible cause of the $\mathrm{ER}_{\mathrm{CO} / \mathrm{CO}_{2}}$ departures seen in Fire 1 from those seen in the other fires (particularly Fires 3 and 4).

The fire averaged emissions ratios (calculated from the separate stage ERs weighted by the per-stage FRE) are reported in Table 3, as is the mean and range of all these "fire averaged" values. Though the emissions ratio characteristics of the RSC stage can be significantly different to those of the flaming stages, the FRE data indicate that for all fires the vast majority of fuel consumption took place in the headfire stage (see Table 1), and so the "fire averaged" ERs are dominated by the headfire contribution. This suggests that under conditions where FRE or other fuel consumption measurements are unavailable, including at unplanned grassfires, emissions ratio characterisation using smoke emanating from the main fire front and neighbouring smoking zone is likely to be a relatively good representation of the "fire averaged" values, agreeing with the basic conclusions of Cofer et al. (1996). In areas with greater amounts of woody fuel, consideration of emissions from the RSC stage is likely to be more important (Bertschi et al., 2003).

Comparisons can be made between our fire averaged ERs and those from prior studies, noting that our "fire averaged" values are dominated by the headfire contribution and were made within a few tens of seconds of the smoke being produced in the combustion zone. Many chemical species transform as smoke ages, and thus the measurement timing in relation to the causal fire should be carefully considered in any comparison (Hobbs et al., 2003). Table 3 includes the relevant mean $\mathrm{ER}_{\mathrm{x} / \mathrm{CO}_{2}}$ values reported by Sinha et al. (2003) for non-aged fire smoke in lofted plumes sampled from similar KNP fires as those studied here, but derived via airborne sampling and gas chromatography/closed-path FTIR 
spectroscopy. Comparison of the current $\mathrm{ER} \mathrm{CO} / \mathrm{CO}_{2}$ results to those of Sinha et al. (2003) indicates some overlap in the values derived via the two approaches, despite the very different sampling and measurement approaches applied. Our values are generally towards the upper end of those reported by Sinha et al. (2003), possibly reflecting a tendency for the ground-based extended open-path approach to preferentially sample the products from less intensely burning areas of combustion (i.e. those that include more smouldering emissions), whilst airborne sampling preferentially targets smoke from intensely lofted plumes generated by higher intensity (i.e. increased flaming) areas. Our ground-based sampling, for example, may include a greater contribution from the headfire "smoking zone" than would have been the case with airborne sampling. Values of $\mathrm{ER}_{\mathrm{x}} / \mathrm{CO}$ for $\mathrm{CH}_{4}$ and $\mathrm{CH}_{2} \mathrm{O}$ are also relatively similar to those reported by Sinha et al. (2003),

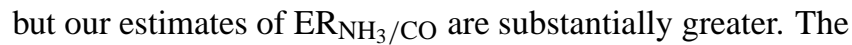
potential reasons for this departure are discussed in the following Section.

Examining the RSC stage in particular, and comparing our emission ratios to those of Bertschi et al. (2003) and Christian et al. (2007) for smouldering logs undergoing residual smouldering combustion (shown at the end of Table 3), indicates a somewhat similar $\mathrm{ER}_{\mathrm{CO} / \mathrm{CO}_{2}}$ for Fires 3 and 4 to that seen in these past works, with values significantly higher than those measured during the headfire and backfires stages of the same fires. However, Fire 1 (and also Fire 2) again departs from this trend. Smouldering log emission ratios for the other trace gases are given by Bertschi et al. (2003) and Christian et al. (2007) with respect to $\mathrm{CO}$ rather than $\mathrm{CO}_{2}$,

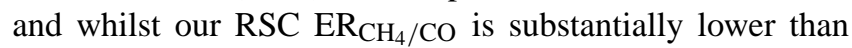
these past works, those of formaldehyde and ammonia are similar.

\subsection{Emissions factors}

Calculated emission factors for each stage of each fire, derived from the ERs via the carbon mass balance approach detailed in Sect. 3.5.2, are listed in Table 4 and shown graphically in Fig. 9. Uncertainties were calculated in quadrature from those associated with the trace gas ERs and the $\pm 10 \%$ uncertainty in the assumed fuel carbon content. As with the "fire averaged" emission ratio calculation described in Sect. 4.1, fire averaged EFs for each species were calculated by weighting the individual stage EFs measures by the proportion of total fuel consumption estimated to have occurred in that stage, as calculated from the per-stage FRE measures. We also report the mean $( \pm 1 \sigma)$ of these "fire averaged" measures. Table 4 also includes the EFs reported for southern African savannah fires by Sinha et al. (2003), which they calculated from their measured ERs that we list in Table 3. Also listed are EFs taken from the SAFARI-92 KNP airborne study of Cofer et al. (1996), EFs from the widely used database of Andreae and Merlet (2001 and updates), from Akagi et al. (2011), and from the SAFARI-92 and SAFARI-2000 campaigns (Ward et al., 1996 and Keene et al., 2006 respectively). Our fire averaged EFs for $\mathrm{CO}_{2}$ are very similar to those of all these past studies, with a mean fire averaged $\mathrm{EF}_{\mathrm{CO}_{2}}$ just $2.1 \%$ different than that calculated by Sinha et al. (2003) using airborne sampling in the same $\mathrm{KNP}$ area. Our fire averaged $\mathrm{EF}_{\mathrm{CH}_{4}}$ values are also similar to those of the quoted past works, but apart from Fire 2 our "fire averaged" $\mathrm{EF}_{\mathrm{CO}}$ values are generally higher than the means determined in most past studies, though still within the range reported by Ward et al. (1996) and Keene et al. (2006). This maybe further indication of the tendency of the ground-based long-path OP-FTIR approach to sample smoke from less intense (i.e. lower combustion efficiency) areas of burning than might be available for sampling at higher altitudes.

In contrast to the relatively strong agreement between our EFs and those presented by Andreae and Merlet (2001) for the dominant carbonaceous species, we find the EF of formaldehyde to be significantly elevated (by factors of $\sim 3-$ 12 , depending on the fire), though their more recent update included in Table 4 (and the more recent EF database of Akagi et al., 2011) lowers this difference somewhat. Our results therefore confirm the findings of Sinha et al. (2003) and Yokelson et al. (2003) of significant departures from literature values of savannah fire $\mathrm{EF}_{\mathrm{CH}_{2} \mathrm{O}}$, a species directly involved in the production of tropospheric ozone. However, unlike these prior works we do not find really major differences between our $\mathrm{NH}_{3}$ emission factors and those presented by Andreae and Merlet (2001) and its updates, and indeed our results are closer to the values quoted in Andreae and Merlet (and to the more recent Akagi et al., 2011) than to the substantially lower values reported by Sinha et al. (2003). We note that without appropriate subtraction of the ambient emission signal (which Fig. 4 confirms is highly significant at the lower wavenumbers used to retrieve ammonia) our $\mathrm{NH}_{3}$ column amounts and thus $\mathrm{EF}_{\mathrm{NH}_{3}}$ would be underestimated by $\sim 60 \%$. Thus we were careful to utilize the approach of Müller et al. (1999) when retrieving $\mathrm{NH}_{3}$ column amounts and, rather than ambient background influences, the cause of the discrepancy in $\mathrm{EF}_{\mathrm{NH}_{3}}$ may be the contrasting measurement methodologies used here and by Sinha et al. (2003) and Yokelson et al. (2003). In particular, Yokelson et al. (2003) identified $\mathrm{NH}_{3}$ to be the only targeted species whose concentration was noticeably affected by the brief residence time spent in the closed cell used to contain the sample. Underestimations of up to $50 \%$ were apparently seen in pre-flight laboratory tests, but after an algorithmic correction was developed $\mathrm{EF}_{\mathrm{NH}_{3}}$ underestimations were reduced to perhaps 5$20 \%$ (Yokelson et al., 2003). Our open path method does not suffer from this effect, potentially explaining at least some of the noted difference in $\mathrm{EF}_{\mathrm{NH}_{3}}$. Another point is that of all the flaming stages measured here, those where our $\mathrm{EF}_{\mathrm{CO}}$ closely approaches that of Sinha et al. (2003) (e.g. the backfire of Fire 2, and to a lesser degree that of Fires 3 and 4) have an $\mathrm{EF}_{\mathrm{NH}_{3}}$ that agrees better with that of Sinha et al. (2003), further indication that a significant part of the divergence seen at 
Table 4. Emissions factors ( $\mathrm{g} \mathrm{kg}^{-1}$ of dry fuel burned) determined for the backfire, headfire and residual smouldering combustion (RSC) stages of Fires 1 to 4 using methods described in Sect. 4.2. EFs based on poorly constrained ERs (see Table 3 and Fig. 8) are not shown. "Fire averaged" EFs are calculated using the stage-specific EFs weighted by the FRE-determined proportion of fuel burned in each stage (apart from for Fire 4 where FRE data are unavailable). Weighted mean EF and its associated uncertainty, calculated according to Taylor (1997), is also shown. Comparison EFs for the same geographical area derived in four different studies using a variety of sampling and measurement techniques are listed, as are those for the "savannah and grassland" category reported in the widely used EF database of Andreae and Merlet (2001) and its more recent updates, and the "savannah" category of the recent EF review by Akagi et al. (2011). We also include EFs from the study of Bertschi et al. (2003), where the FTIR-derived emissions factors for a group of tropical wooded savannah logs from Zambia were measured whilst undergoing RSC, and used to calculate a "total" fire integrated wooded savannah EF in combination with EF measurements from lofted emissions sampled via airborne FTIR. The simple linear model adopted by Bertschi et al. (2003) for the wooded savannah assumed that $10 \%$ of all fuel consumption occurred in RSC combustion, and the remainder in combustion that resulted in emissions of the sort sampled by the lofted emissions measurement approach. Finally we include EFs for a follow on study of RSC performed by Christian et al. (2007) in Brazil, quoting both the EFs of logs undergoing smouldering combustion, and the total EF of pasture fires including a $40 \%$ contribution from RSC.

\begin{tabular}{|c|c|c|c|c|c|c|}
\hline $\begin{array}{l}\text { Fire } \\
\text { No. }\end{array}$ & $\begin{array}{l}\text { Emission } \\
\text { Factor }\end{array}$ & $\begin{array}{l}\mathrm{CO}_{2} \\
\left(\mathrm{~g} \mathrm{~kg}^{-1}\right)\end{array}$ & $\begin{array}{l}\mathrm{CO} \\
\left(\mathrm{g} \mathrm{kg}^{-1}\right)\end{array}$ & $\begin{array}{l}\mathrm{CH}_{4} \\
\left(\mathrm{~g} \mathrm{~kg}^{-1}\right)\end{array}$ & $\begin{array}{l}\mathrm{CH}_{2} \mathrm{O} \\
\left(\mathrm{g} \mathrm{kg}^{-1}\right)\end{array}$ & $\begin{array}{l}\mathrm{NH}_{3} \\
\left(\mathrm{~g} \mathrm{~kg}^{-1}\right)\end{array}$ \\
\hline 1 & Head & $1655 \pm 166$ & $106 \pm 12$ & $2.8 \pm 0.4$ & $2.5 \pm 0.3$ & $1.3 \pm 0.2$ \\
\hline 1 & Back & $1632 \pm 163$ & $118 \pm 13$ & $3.6 \pm 0.4$ & $3.6 \pm 0.6$ & $1.1 \pm 0.2$ \\
\hline \multirow[t]{2}{*}{1} & RSC & $1661 \pm 167$ & $101 \pm 17$ & $4.0 \pm 0.8$ & $1.9 \pm 0.5$ & $2.1 \pm 0.4$ \\
\hline & Fire 1 Averaged & $1652 \pm 166$ & $108 \pm 13$ & $2.9 \pm 0.4$ & $2.6 \pm 0.3$ & $1.3 \pm 0.2$ \\
\hline 2 & Head & $1725 \pm 173$ & $68 \pm 9$ & $1.5 \pm 0.3$ & $1.4 \pm 0.3$ & - \\
\hline 2 & Back & $1726 \pm 173$ & $65 \pm 9$ & $1.2 \pm 0.2$ & $1.8 \pm 0.2$ & $0.27 \pm 0.07$ \\
\hline \multirow[t]{2}{*}{2} & RSC & $1721 \pm 172$ & $67 \pm 8$ & $1.9 \pm 0.3$ & $1.5 \pm 0.2$ & $0.60 \pm 0.09$ \\
\hline & Fire 2 Averaged & $1725 \pm 173$ & $68 \pm 9$ & $1.5 \pm 0.3$ & $1.4 \pm 0.3$ & - \\
\hline 3 & Head & $1621 \pm 168$ & $127 \pm 36$ & $3.2 \pm 1.1$ & $3.0 \pm 0.8$ & $1.5 \pm 0.65$ \\
\hline 3 & Back & $1701 \pm 170$ & $80 \pm 11$ & $1.4 \pm 0.3$ & $1.7 \pm 0.3$ & $0.53 \pm 0.14$ \\
\hline 3 & RSC & $1539 \pm 154$ & $170 \pm 18$ & $7.9 \pm 0.8$ & $3.3 \pm 0.5$ & $3.2 \pm 0.62$ \\
\hline & Fire 3 Averaged & $1620 \pm 168$ & $127 \pm 35$ & $3.3 \pm 1.1$ & $3.0 \pm 0.8$ & $1.5 \pm 0.64$ \\
\hline 4 & Head & $1696 \pm 171$ & $85 \pm 19$ & - & $2.2 \pm 0.4$ & - \\
\hline 4 & Back & $1708 \pm 171$ & $75 \pm 9$ & $1.3 \pm 0.2$ & $2.1 \pm 0.2$ & $0.59 \pm 0.09$ \\
\hline \multirow[t]{13}{*}{4} & $\mathrm{RSC}$ & $1477 \pm 149$ & $211 \pm 25$ & $7.0 \pm 1.0$ & $4.2 \pm 0.5$ & $3.71 \pm 0.47$ \\
\hline & $\begin{array}{l}\text { "Fire Averaged" } \\
\text { mean }( \pm \sigma)\end{array}$ & $1665 \pm 54$ & $101 \pm 30$ & $2.5 \pm 0.9$ & $2.3 \pm 0.8$ & $1.4 \pm 0.1$ \\
\hline & Sinha et al. (2003) & $1700 \pm 60$ & $68 \pm 30$ & $1.7 \pm 1.0$ & $1.1 \pm 0.38$ & $0.26 \pm 0.14$ \\
\hline & Cofer et al. (1996) & $1610 \pm 380$ & $55 \pm 13$ & $3 \pm 2$ & - & - \\
\hline & Keene et al. (2006) & $\begin{array}{l}1319 \text { to } \\
1967\end{array}$ & 42 to 108 & - & - & 0.03 to 1.37 \\
\hline & Ward et al. (1996) & $\begin{array}{l}1643 \text { to } \\
1735\end{array}$ & 58 to 105 & 1.5 to 4.7 & - & - \\
\hline & Andreae and Merlet (2001) & $1613 \pm 95$ & $65 \pm 20$ & $2.3 \pm 0.9$ & 0.26 to 0.44 & 0.6 to 1.05 \\
\hline & $\begin{array}{l}\text { Andreae and Merlet } \\
\text { (personal communication, } \\
\text { 2009) }\end{array}$ & $1646 \pm 99$ & $61 \pm 16$ & $2.2 \pm 0.8$ & $0.71 \pm 0.42$ & $0.74 \pm 0.55$ \\
\hline & Akagi et al. (2011) & $1686 \pm 38$ & $63 \pm 17$ & $1.94 \pm 0.8$ & $0.73 \pm 0.62$ & $0.52 \pm 0.35$ \\
\hline & $\begin{array}{l}\text { Bertschi et al. (2003) } \\
\text { [RSC emissions] }\end{array}$ & 1454 & 158 & 23.2 & 3.48 & 1.92 \\
\hline & $\begin{array}{l}\text { Bertschi et al. (2003) [Total } \\
\text { wooded savannah emissions] }\end{array}$ & 1685 & 78 & 3.6 & 1.02 & 0.55 \\
\hline & $\begin{array}{l}\text { Christian et al. (2007) } \\
\text { [RSC emissions] }\end{array}$ & 1343 & 229 & 17.1 & 1.9 & 1.64 \\
\hline & $\begin{array}{l}\text { Christian et al. (2007) } \\
\text { [Total pasture emissions] }\end{array}$ & 1512 & 161 & 10.4 & 1.24 & 1.43 \\
\hline
\end{tabular}



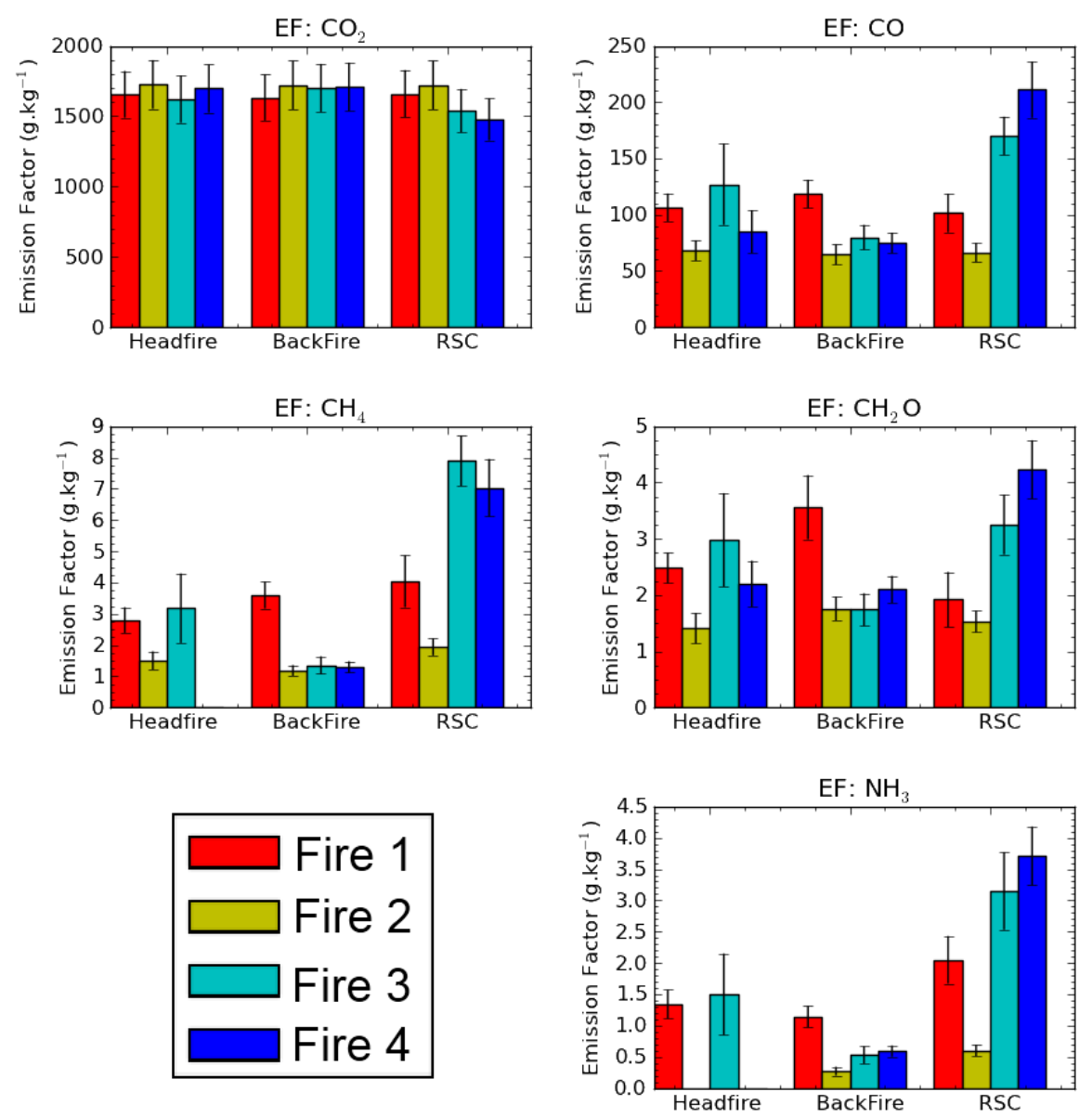

Fig. 9. Emissions factors $\left[\mathrm{EF}_{\mathrm{X}}\right]$ for $\mathrm{CO}_{2}, \mathrm{CO}, \mathrm{CH}_{2} \mathrm{O}$ and $\mathrm{NH}_{3}$ for the backfire, headfire and residual smouldering combustion stages (RSC) of Fires 1, 2, 3 and 4 (see Table 1 for fire details). Error bars provide a measure of emissions factor uncertainty, derived in quadrature from the uncertainty in the relevant emission ratios and a $\pm 10 \%$ uncertainty in the assumed fuel $\mathrm{C}$ content. Missing values represent cases where the relevant $\mathrm{ER}_{\mathrm{x} / \mathrm{CO}_{2}}$ measure was poorly constrained, based on a low coefficient of determination $\left(r^{2}\right)$ between the two relevant trace gas column amounts (See Figs. 7 and 8).

other times may be due to differences between ground-based sampling (tending to sample a higher proportion of smoke from smouldering processes) and airborne sampling (tending to sample a higher proportion of smoke from flaming processes). A further contributory factor may come from the work of Keene et al. (2006), who found fuel-specific $\mathrm{EF}_{\mathrm{NH}_{3}}$ to differ substantially between the different KNP fuel components, most probably due to differing nitrogen contents, and Christian et al. (2007) who report a particularly high $\mathrm{EF}_{\mathrm{NH}_{3}}$ $\left(5.5 \mathrm{~g} \mathrm{~kg}^{-1}\right)$ for smouldering dung. This makes each $\mathrm{EF}_{\mathrm{NH}_{3}}$ highly dependent upon the mix of fuels consumed, and suggests potentially high variability across space and time.
In terms of our RSC emission factor measures, Table 4 includes results from Bertschi et al. (2003) and Christian et al. (2007) for comparison. Our RSC $\mathrm{EF}_{\mathrm{CO}_{2}}$ values fall as low as $1477 \pm 149 \mathrm{~g} \mathrm{~kg}^{-1}$, which is similar to the RSC value of $1454 \mathrm{~g} \mathrm{~kg}^{-1}$ determined by Bertschi et al. (2003) for smouldering logs, and a little higher than the $1343 \mathrm{~g}$ $\mathrm{kg}^{-1}$ determined by Christian et al. (2007) for similar fuels. However, whilst these former studies targeted emissions from only smouldering logs, our RSC sample comes from all smoke being generated in the RSC stage, which included areas of residual flaming activity (albeit unassociated with a flaming front), such as parts of standing trees, downed woody debris and also dung. Our RSC $\mathrm{EF}_{\mathrm{CO}}$ (and $\mathrm{EF}_{\mathrm{CH}_{2}} \mathrm{O}$ ) values do rise to levels seen in Bertschi et al. (2003) and Christian et al. (2007) during Fires 3 and 4 (and 1), though our $\mathrm{EF}_{\mathrm{CH}_{4}}$ values remain substantially below those reported in

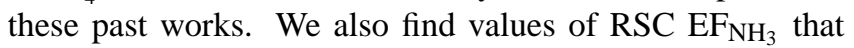


rise substantially above those previously reported. Comparing our "fire averaged" results with those given by Bertschi et al. (2003) and Christian et al. (2007) (whose calculation was based upon an assumed a fixed proportion of fuel consumption in the separate flaming and RSC stages), we find our $\mathrm{EF}_{\mathrm{CO}_{2}}, \mathrm{EF}_{\mathrm{CO}}$ and $\mathrm{EF}_{\mathrm{NH}_{3}}$ to be intermediate between these past reports, $\mathrm{EF}_{\mathrm{CH}_{4}}$ to be substantially lower and $\mathrm{EF}_{\mathrm{CH}_{2} \mathrm{O}}$ higher. However, our FRE-based relative fuel consumption measures (Table 1) indicate that much smaller amounts of fuel are burned in the RSC stage of these savannah fires when compared to the $10 \%$ and $40 \%$ contributions respectively assumed by Bertschi et al. (2003) and Christian et al. (2007).

\subsection{MCE and fire pixel brightness temperature}

Since flaming combustion occurs at a higher temperature than smouldering combustion (Lobert and Warnatz, 1993) it has been suggested that fire temperature estimates derived from airborne or spaceborne remote sensing may be useful in broadly classifying combustion into predominately flaming (i.e. higher MCE) or smouldering (i.e. lower MCE) activity (e.g. Dennision et al., 2006; Zhukov et al., 2006). Since ERs and EFs can clearly vary substantially between these combustion processes, such discrimination may in future be able to enhance emissions estimation procedures. Since both plume MCE and fire pixel brightness temperature (BT) data are available for the headfire and RSC Stages of Fires 1 and 3 we have some opportunity to examine this potential. Our conclusions must be limited however, since without multispectral airborne IR data we can examine pixel-integrated BTs only, which will be lower than the fires true radiative temperature when the area of combustion under-fills the pixels. This issue is less significant at the small pixel sizes used here, but would preclude such a simple analysis when using satellite-derived IR BT measures. Our pixel-integrated BT measures are also likely to be affected by variations in flame depth, soot production and other fire processes, but nevertheless the final two panels of Fig. 6 do demonstrate that the per-spectrum MCE values (calculated using Eq. 7) and the remotely sensed fire pixel brightness temperatures show a degree of temporal similarity, decreasing slowly during the headfire and then more rapidly during the RSC stage. This plot also suggests that that the fires spatial extent, which is seen to have a dramatic effect on FRP (e.g. the FRP peak around $23 \mathrm{~min}$ into the burn, when the area of recorded flaming combustion appears to be towards its maximum according to the thermal imagery) has no noticeable effect on MCE. Data from Fire 3 confirm the general pattern seen in Fire 1, i.e. as the combustion moves from flaming-dominated to more smouldering-dominated processes, and MCE decreases from a headfire value of $0.89 \pm 0.05$ to an RSC value of $0.85 \pm 0.01$, the fire BTs also tend to decrease. However, whilst the corresponding $\mathrm{ER}_{\mathrm{co} / \mathrm{co}_{2}}$ increases by $\sim 40 \%$ between the headfire and RSC stages of Fire 3, the remotely sensed BT decrease seems less significant (max BT: headfire
$595 \pm 62 \mathrm{~K}$ vs. RSC $555 \pm 41 \mathrm{~K}$; mean BT: headfire $520 \pm 17$ vs. backfire $490 \pm 7 \mathrm{~K}$ ). Given the relative imprecision of sub-pixel fire radiometric temperature estimates derivable from current moderate spatial resolution spaceborne imagery (with typical uncertainties of hundreds of Kelvin: Giglio and Kendall, 2001; Zhukov et al., 2006), the prospects for tailoring smoke emissions factors of individual fire events based on satellite-derived fire temperatures appears rather weak, at least until improvements in spatial resolution and/or spectral band number enable improved temperature retrievals.

\section{Summary and conclusions}

Following an early demonstration by Griffith et al. (1991), extended OP-FTIR spectroscopy has been relatively little exploited for vegetation fire plume analysis, but reductions in size and cost, and increases in the performance and availability of Stirling-cooled detector systems have made such deployments increasingly practicable. This paper reports results from a unique, high temporal resolution biomass burning trace gas emission dataset collected using extended OPFTIR spectroscopy at a series of multi-hectare savannah fires conducted in Kruger National Park (South Africa). The OPFTIR setup measuring across pathlengths of $150-250 \mathrm{~m}$ allowed multiple smoke chemical constituents to be probed simultaneously and at a very high temporal resolution across a large proportion (or even the totality) of the advected plume cross section, avoiding many limitations of point-sampling approaches. The near-ground parts of the smoke column were able to be probed well before any significant physical and chemical "ageing" processes took effect. These groundbased measurements were supplemented by airborne optical and thermal imaging from a helicopter hovering above the burning plots, allowing for the determination of fire radiative power (FRP) and fire radiative energy (FRE) measures. We focused on a set of key compounds related preferentially to pyrolysis $\left(\mathrm{CH}_{2} \mathrm{O}\right)$, flaming $\left(\mathrm{CO}_{2}\right)$ and smoldering $(\mathrm{CO}$, $\mathrm{CH}_{4}, \mathrm{NH}_{3}$ ) processes. Trace gas column amounts for these species were derived from the single beam IR spectra using a spectral forward model coupled to a non-linear least squares fitting approach, avoiding the need for experimentally determined reference spectra. The method is sufficiently sensitive to detect, for example, path-averaged $\mathrm{CO}$ mixing ratio variations of $\sim 0.01 \mu \mathrm{mol} \mathrm{mol}^{-1}[10 \mathrm{ppbv}]$ across the $150-250 \mathrm{~m}$ optical paths used here.

The retrieved trace gas column amounts allow for the calculation of emissions ratios (ERs) and emissions factors (EFs) for each stage of the studied fires (headfire, backfire and residual smouldering combustion), and the availability of stage-specific fire radiative energy (FRE) measures allowed for the determination of "fire averaged" ERs and EFs using a weighted-mean approach. We agree with previous works that, with $\mathrm{CO}_{2}$ as the reference species, ERs from the RSC stage are mostly higher than for the flaming stages, and 
our results for the RSC stage show some similarities to the measurements of smouldering logs presented by Bertschi et al. (2003) and Christian et al. (2007). Our FRE data suggest that only a few percent of total fuel consumption actually occurs in the RSC stage of these savannah burns, so even though ERs and EFs are substantially higher for many compounds in the RSC stage, sampling of headfire activity alone actually may be sufficient for general assessment of "fire averaged" ERs and EFs in this particular environment.

We find ERs for headfires and backfires to be similar, and often rather different that those seen in the RSC stage. Apart from for ammonia, our mean "fire averaged" ERs lie reasonably close to those calculated previously by Sinha et al. (2003) via airborne sampling in Kruger National Park, though they tend to be somewhat higher (by between 17 and $47 \%$; see Table 3). $\mathrm{CO}_{2}$ and $\mathrm{CH}_{4}$ emissions factors derived from the relevant emission ratios also show good agreement with published studies, including the databases of Andreae and Merlet (2001 and subsequent updates) and Akagi et al. (2011). However, our mean fire averaged EF for carbon monoxide $\left(101 \pm 30 \mathrm{~g} \mathrm{~kg}^{-1}\right)$ lies towards the top end of most previous measurements (apart from those directly targeting smouldering activity; see Table 4), which suggests our long pathlength OP-FTIR approach may sample a greater proportion of smoke from smouldering processes when compared to airborne sampling (which usually targets lofted emissions generated by more intensely burning areas), or point-based ground measurements where flaming zones are able to be directly sampled. The plume rise we saw at these 7 ha fires was in fact quite limited (estimated at $\sim 50 \mathrm{~m}$ in the area immediately surrounding the plot), probably because of the moderate fuel loads and modest fire areas (Table 1). Much more substantial vertically rising plumes (rising up to more than $1 \mathrm{~km}$ altitude) have been reported for larger fires in KNP (Hobbs et al., 2003). Nevertheless, our ground-based results generally show a lower MCE than the airborne results of Sinha et al. (2003), and a higher EF for species associated with lower MCE, and this does imply that different smoke tends to be probed from the ground and airborne vantage points. Another contributing factor in these differences maybe that our use of the most recent HITRAN 2008 database increases the derived $\mathrm{EF}_{\mathrm{CO}}$ by $\sim 20 \%$ when compared to use of older HITRAN versions.

For formaldehyde, our results indicate the EF to be very significantly higher than currently reported estimates, even that of Sinha et al. (2003). This may point to substantial biases in the total emission estimates calculated for this species for savannah environments, which will pose problems when comparing bottom-up (e.g. emissions inventories) and topdown (e.g. satellite-derived column totals) estimates of this trace gas. Such effects may be in part responsible for the low-biased $\mathrm{CH}_{2} \mathrm{O}$ emissions totals reported by Stavrakou et al. (2009) when compared to satellite EO-derived formaldehyde columns. We also find the EF for ammonia to be closer to that of Andreae and Merlet (2001) than to the lower Sinha et al. (2003) values. Finally, our work indicates that burning elephant dung can contribute substantially to the emissions characteristics in KNP, altering the chemistry of the fire plumes from what they would be in the absence of this additional fuel component.

Our work has confirmed ground-based, extended OPFTIR as a practical, rapidly deployable, relatively low cost yet effective means of ER and EF determination for open vegetation fires burning in a manner broadly representative of wildfire phenomena. However, the approach does require the smoke to be blown near horizontally into the measurement path, so smoke from lofted plumes remains difficult to sample and many OP-FTIR campaigns would thus benefit from being conducted in unison with some form of airborne sampling. We concur with Guyon et al. (2005) that a combination of both airborne and ground-based sampling approaches, in which OP-FTIR maybe an important component, most likely offers the most complete approach to "whole fire" ER and EF determination. If the airborne platform also carried a suitable IR imaging device, then fire radiative power measurements might also be derivable for use in assessing "fire averaged" ER and EF quantities, avoiding some of the assumptions regarding fuel consumption required in the "whole fire" calculations used by Bertschi et al. (2003) and Christian et al. (2007), who were amongst the first to estimate the significance of the RSC contribution. We note that, although we limited our study to only five chemical species, the measured IR spectra theoretically allow quantification of dozens of other molecules should they be present in significant quantities (Yokelson et al., 1999; Sinha et al., 2003, 2003b, 2004).

The extended OP-FTIR technique could in future allow study of as-yet poorly characterised combustion situations, such as smouldering peat fires and the night-time chemistry occurring in smoke-filled valleys. Ground-based OP-FTIR deployments on rapidly spreading wildfires maybe difficult however, as the downwind open path may lie in the general direction in which the fire travels. In such cases, and in order to sample lofted plumes, it may be possible to adapt the method to encompass a solar-occultation viewing geometry, an approach which has already proven successful in studies of high altitude volcanic plumes (Francis et al., 1998; Duffell et al., 2001) and smoke-polluted atmospheres (e.g. PatonWalsh et al., 2005; 2008).

Acknowledgements. Financial support for parts of this scientific research came from the NERC National Center for Earth Observation (NCEO) and the European Commission, which funded the project "CarboAfrica" (GOCE, 037132) under the 6th Framework Programme (FP6). Professor Riccardo Valentini and colleagues of the Laboratory of Forest Ecology, University of Tuscia (Italy) are thanked for support in the field. Antonio Bombelli of the same laboratory provided logistical assistance, and Gerado Fratini the LICOR IR Gas Analyser measures. We are indebted to South African National Parks for their great assistance with many aspects of this study and for access to their data. Bob Scholes (CSIR Natural Resources and the Environment) helped formulate this 
collaboration and provided invaluable advice in the field. The role of the team that maintained the KNP fire experiment (especially Andre Potgieter) is gratefully acknowledged, as is that of the NERC Field Spectroscopy Facility (FSF), particularly Chris Maclellan and Alasdair Mac Arthur, who procured the OP-FTIR system used here (loaned from NERC FSF) and who provided invaluable advice, support and logistical assistance related to the deployment. Meinrat Andreae is thanked for providing updates to the Andreae and Merlet (2001) EF database. Nathan Wooster and Alec Wooster are thanked for their support and for assistance with OP-FTIR setup evaluation in the UK prior its field deployment. Finally, we are grateful to Georgina Sawyer of the Department of Geography, University of Cambridge (UK) for her advice on FTIR retrieval specifics using the code deployed here, and to Bob Yokelson of the University of Montana (USA), David Griffith of the University of Wollongong (Australia) and an anonymous reviewer for their extremely incisive, detailed comments that helped improve the content and clarity of this manuscript.

Edited by: R. Holzinger

\section{References}

Akagi, S. K., Yokelson, R. J., Wiedinmyer, C., Alvarado, M. J., Reid, J. S., Karl, T., Crounse, J. D., and Wennberg, P. O.: Emission factors for open and domestic biomass burning for use in atmospheric models, Atmos. Chem. Phys., 11, 4039-4072, doi:10.5194/acp-11-4039-2011, 2011.

Andreae, M. O. and Merlet, P.: Emission of trace gases and aerosols from biomass burning, Global Biogeochem. Cy., 15, 955-966, 2001

Archibald, S., Nickless, A., Govender, N., Scholes, R.J., Lehsten, V. Climate and the inter-annual variability of fire in southern Africa: a meta-analysis using long-term field data and satellite-derived burnt area data, Global Ecol. Biogeogr., 19, 794-809, 2010.

Bacsik, Z., Voktoria, K., Ollar, T., and Mink, J.: Comparison of Open Path and Extractive Long-Path FTIR Techniques in Detection of Air Pollutants, Appl. Spectrosc. Rev., 41, 77-97, 2006.

Benner, D. C., Rinsland, C. P., Devi, V. M., Smith, M. A. H., and Atkins, D. A.: Multi-spectrum nonlinear least squares fitting technique, J. Quant. Spectrosc Ra., 53, 705-721, 1995.

Bertschi, I., Yokelson, R. J., Ward, D. E., Babbitt, R. E., Susott, R. A., Goode, J. G., and Hao, W.: Trace gas and particle emissions from fires in large diameter and belowground biomass fuels, J. Geophys. Res., 108, 8472, doi:8410.1029/2002JD002100., 2003.

Bowman, D. M., Balch, J. K., Artaxo, P., Bond, W. J., Carlson, J. M., Cochrane, M. A., D’Antonio, C. M., Defries, R. S., Doyle, J. C., Harrison, S. P., Johnston, F. H., Keeley, J. E., Krawchuk, M. A., Kull, C. A., Marston, J. B., Moritz, M. A., Prentice, I. C., Roos, C. I., Scott, A. C., Swetnam, T. W., van der Werf, G. R., Pyne, S. J. Fire in the Earth system, Science, 324, 481-484, 2009.

Briz, S., de Castro, A. J., Diez, S., Lopez, F., and Schafer, K.: Remote sensing by open-path FTIR spectroscopy. Comparison of different analysis techniques applied to ozone and carbon monoxide detection, J. Quant. Spectrosc Ra., 103, 314-330, 2007

Burling, I. R., Yokelson, R. J., Griffith, D. W. T., Johnson, T. J., Veres, P., Roberts, J. M., Warneke, C., Urbanski, S. P., Rear- don, J., Weise, D. R., Hao, W. M., and de Gouw, J.: Laboratory measurements of trace gas emissions from biomass burning of fuel types from the southeastern and southwestern United States, Atmos. Chem. Phys., 10, 11115-11130, doi:10.5194/acp10-11115-2010, 2010.

Burton, M.: Remote Sensing of the Atmosphere Using Fourier Transform Spectroscopy, PhD. Thesis, University of Cambridge, Cambridge, UK, 1998.

Burton, M. R., Oppenheimer, C., Horrocks, L. A., and Francis, P. W.: Remote sensing of $\mathrm{CO}_{2}$ and $\mathrm{H}_{2} \mathrm{O}$ emission rates from Masaya volcano, Nicaragua, Geology, 28, 915-918, 2000.

Castro, A. J., Lerma, A. M., Lpez, F., Guijarro, M., Dez, C., Hernando, C., and Madrigal, J.: Open-path Fourier transform infrared spectrometry characterization of low temperature combustion gases in biomass fuels, Infrared Phys. Techn., 51, 21-30, 2007.

Childers, J. W., Thomson, E. L., Harris, D. B, Kirchgessner, D. A., Clayton, M., Natschke, D. F., and Phillips, W. J.: Multi-pollutant concentration measurements around a concentrated swine production facility using open-path FTIR spectrometry, Atmos. Environ., 35, 1923-1936, 2001.

Christian, T. J., Yokelson, R. J. Carvalho Jr., J. A. Griffith, D. W. T., Alvarado, E. C., Santos, J. C., Neto, T. G. S., Veras, C. A. G., and Hao, W. M.: The tropical forest and fire emissions experiment: Trace gases emitted by smoldering logs and dung from deforestation and pasture fires in Brazil, J. Geophys. Res., 112, D18308, doi:10.1029/2006JD008147, 2007.

Crockett, J. S. and Engle, D. M.: Combustion characteristics of Bison, Bison Bison. fecal pats ignited by grassland fires, Am. Midl. Nat., 141, 12-18, 1999.

Cofer, W. R., III, Levine, J. S., Winstead, E. L., Cahoon, D. R., Sebacher, D. I., Pinto, J. P., and Stocks, B. J.: Source compositions of trace gases released during African savanna fires, J. Geophys. Res. , 101, 23,597-23,602, 1996.

Delmas, R., Lacaux, J. P., Brocard, D.: Determination of biomass burning emission factors: Methods and results, Environ. Monit. Assess., 38, 181-204, 1995.

Dennison, P. E., Charoensiri, K., Roberts, D. A., Peterson, S. H., and Green, R. O.: Wildfire temperature and land cover modeling using hyperspectral data, Remote Sens. Environ., 100, 212-222, 2006.

Disney, M. I., Lewis, P., Gomez-Dans, J., Roy, D., Wooster, M. J., and Lajas, D.: 3D radiative transfer modelling of fire impacts on a two-layer savanna system, Remote Sens. Environ., 115, 18661881, 2011.

Duffell, H., Oppenheimer, C., and Burton, M. R.: Volcanic gas emission rates measured by solar occultation spectroscopy, Geophys. Res. Lett., 28, 3131-3134, 2001.

Edwards, D. J. and Dudhia, A.: Reference Forward Model: High level algorithms definition, ESA Doc. POMA-OXF-GS-0004, European Space Agency, Paris, 1996.

Francis, P., Burton, M., and Oppenheimer, C.: Remote measurements of volcanic gas compositions by solar FTIR spectroscopy, Nature, 396, 567-570, 1998.

Freeborn, P. H., Wooster, M. J., Hao, W. M., Ryan, C. A., Nordgren, B. L. Baker, S. P., and Ichoku, C.: Relationships between energy release, fuel mass loss, and trace gas and aerosol emissions during laboratory biomass fires, J. Geophys. Res., 113, D01102, doi:10.1029/2007JD008489, 2008. 
Freeborn, P. H., Wooster, M. J., Roberts, G., Malamud, B., and $\mathrm{Xu}, \mathrm{W}$. : Development of a virtual active fire product for Africa through a synthesis of geostationary and polar orbiting satellite data, Remote Sens. Environ., 113, 1700-1711, 2009.

Fernández-Gómez, I., de Castro, A. J., Guijarro, M., Madrigal, J., Aranda, J. M., Diez, C., Hernando, C., and Lopez, F.: Characterization of forest fuels in a Mass Loss Calorimeter by short openpath FTIR spectroscopy, J. Quant. Spectrosc. Ra., 112, 519-530, 2011.

Giglio, L. and Kendall, J. D.: Application of the Dozier retrieval to wildfire characterization: A sensitivity analysis, Remote Sens. Environ., 77, 34-49, 2001.

Giglio, L., Loboda, T., Roy, D. P., Quayle, B., and Justice, C. O.: An active-fire based burned area mapping algorithm for the MODIS sensor, Remote Sens. Environ., 113, 408-420, 2009.

Goode, J. G., Yokelson, R. J., Susott, R. A., and Ward, D. E.: Trace gas emissions from laboratory biomass fires measured by openpath FTIR: Fires in grass and surface fuels, J. Geophys. Res. , 104, 21,237-21,245, 2000.

Gosz, J. R., Clifford, N. D., and Risser, P. G.: Long-Path FTIR Measurement of Atmospheric Trace Gas Concentrations, Ecology, 69, 1326-1330, 1988.

Govender, N., Trollope, W. S. W, van Wilgen, B. W.: The effect of fire season, fire frequency, rainfall and management on fire intensities in savanna vegetation in South Africa, J. Appl. Ecol., 43, 748-758, 2006.

Griffith, D.: Synthetic calibration and quantitative analysis of gasphase FT-IR spectra, Appl. Spectrosc., 50, 59-70, 1996.

Griffith, D., W. T., Mankin, W. G., Coffey, M. T., Ward, D. E., and Riebau, A.: FTIR remote sensing of biomass burning emissions of $\mathrm{CO} 2, \mathrm{CO}, \mathrm{Ch}_{4}, \mathrm{CH}_{2} \mathrm{O}, \mathrm{NO}, \mathrm{NO}_{2}, \mathrm{NH}_{3}$ and $\mathrm{N}_{2} \mathrm{O}$, in Global Biomass Burning: Atmospheric, Climatic, and Biospheric Implications, MIT Press, edite by: Levine, J., 230-240, 1991.

Guyon, P., Frank, G. P., Welling, M., Chand, D., Artaxo, P., Rizzo, L., Nishioka, G., Kolle, O., Fritsch, H., Silva Dias, M. A. F, Gatti, L. V., Cordova, A. M., and Andreae, M. O.: Airborne measurements of trace gas and aerosol particle emissions from biomass burning in Amazonia, Atmos. Chem. Phys., 5, 29893002, doi:10.5194/acp-5-2989-2005, 2005.

Hobbs, P. V., Sinha, P., Yokelson, R. J., Christian, T. J., Blake, D. R., Gao, S., Kirchstetter, T. W., Novakov, T., Pilewskie, P., 2003. Evolution of gases and particles from a savanna fire in South Africa, J. Geophys. Res. , 108, 8435, doi:10.1029/2002JD002352.

Horrocks, L.: Infrared spectroscopy of volcanic gases at Masaya, Nicaragua. PhD Thesis, Open University, U.K., 253 pp., 2001.

Hren, B., Katona, K., Mink, J., Kohán J., Isaák, G.Y. Long-path FTIR spectroscopic studies of air pollutants in the Danube refinery plant, Analyst, 125, 1655-1659, 2000.

Kaiser, J., Boucher, O., Doutriaux-Boucher, M., Flemming, J., Govaerts, Y.M., Gulliver, J., Heil, A., Jones, L., Lattanzio, Al., Morcrette, J.-J., Perrone, M. R., Razinger, M., Roberts, G., Schultz, M. G., Simmons, A. J., Suttie, M., and Wooster, M. J.: Smoke in the Air, ECMWF Newsletter No. 119, http://www.ecmwf.int/ publications/newsletters/, 2009.

Keene, W. C., Lobert, J. M., Crutzen, P. J., Maben, J. R., Scharffe, D. H., and Landmann, T.: Emissions of major gaseous and particulate species during experimental burns of southern African biomass, J. Geophys. Res., 111, D04301,
doi:10.1029/2005JD006319, 2006.

Koppmann, R., von Czapiewski, K., and Reid, J. S.: A review of biomass burning emissions, part I: gaseous emissions of carbon monoxide, methane, volatile organic compounds, and nitrogen containing compounds, Atmos. Chem. Phys. Discuss., 5, 1045510516, doi:10.5194/acpd-5-10455-2005, 2005

Korontzi, S., Ward, D. E., Susott, R. A., Yokelson, R. J., Justice, C. O., Hobbs, P. V., Smithwick, E. A. H., and Hao, W. M.: Seasonal variation and ecosystem dependence of emission factors for selected trace gases and PM for southern African savanna fires, J. Geophys. Res., 108, 4758, doi:10.1029/2003JD003730, 2003.

Korontzi, S., Roy, D. P., Justice, C. O., and Ward, D. E.: Modeling and sensitivity analysis of fire emissions in southern Africa during SAFARI 2000, Remote Sens. Environ., 376-396, 2004.

Lacaux, J.-P., Delmas, R., Jambert, C., and Kuhlbusch, T. A. J.: $\mathrm{NO}_{\mathrm{x}}$ emissions from African savanna fires, J. Geophys. Res., 101, 23585-23596, 1996.

Lobert, J. M. and Warnatz, J.: Emissions from the combustion processes in vegetation, in: Fire in the Environments: The Ecological, Atmospheric, and Climatic Importance of Vegetation Fires, edited by: Crutzen, P. J. and Goldammer, J. G., John Wiley and Sons, New York, USA, 1993.

Marquardt, D. W.: An algorithm for least squares estimation of nonlinear problems, J. Soc. Ind. Appl. Math., 11, 431-441, 1963.

Müller, U., Kurte, R., and Heise, H. M.: Investigation of photometric errors in FTIR-spectra obtained in open-path monitoring, J. Mol. Struct., 482-483, 539-544, 1999.

Niple, E.: Non linear least squares analysis of atmospheric absorption spectra, Appl. Optics, 19, 3481-3490, 1980.

Okitsu, S.: Factors controlling geographical distribution in savanna vegetation in Namibia, African Study Monographs, Suppl. 30, 135-151, 2005.

Oppenheimer, C. and Kyle, P.R. Probing the magma plumbing of Erebus volcano, Antarctica, by open-path FTIR spectroscopy of gas emissions, J. Volcanol. Geoth. Res., 1, 743-754, 2007.

Paton-Walsh, C., Jones, N. B., Wilson, S. R., Haverd, V., Meier, A., and Griffith, D. W. T.: Measurements of trace gas emissions from Australian forest fires and correlations with coincident measurements of aerosol optical depth, J. Geophys. Res., 110, D24305, doi:10.1029/2005JD006202, 2005.

Paton-Walsh, C., Wilson, S. R., Jones, N. B., and Griffith, D. W. T.: Measurement of methanol emissions from Australian wildfires by ground-based solar Fourier transform spectroscopy, Geophys. Res. Lett., 35, L08810, doi:10.1029/2007GL032951, 2008.

Reid, J. S., Koppmann, R., Eck, T. F., and Eleuterio, D. P.: A review of biomass burning emissions part II: intensive physical properties of biomass burning particles, Atmos. Chem. Phys., 5, 799825, doi:10.5194/acp-5-799-2005, 2005.

Reid, J. S. Hyer, E. J., Prins, E. M., Westphal, D. L., Zhang, J., Wang, J., Christopher, S. A., Curtis, C. A., Schmidt, C. C., Eleuterio, D. P., Richardson, K. A., and Hoffman, J. P.: Global monitoring and forecasting of biomass-burning smoke: Description of and lessons from the forecasting and modeling of burning emissions, FLAMBE. program, IEEE J. Sel. Top. Appl., 34, 144-162, 2009.

Rodgers, C. D.: Retrieval of atmospheric temperature and composition from remote measurements of thermal radiation, Rev. Geophys. Space Ge., 14, 609-624, 1976.

Roberts, G., Wooster, M. J., Lagoudakis, E.: Annual and diurnal 
african biomass burning temporal dynamics, Biogeosciences, 6 , 849-866, 2009.

Rothman, L. S., Gordon, I. E., Barbe, A., Chris Benner, D., Bernath, P. F., Birk, M., Boudon, V., Brown, L. R., Campargue, A., Champion, J.-P., Chance, K., Coudert, L. H., Danaj, V., Devi, V. M., Fally, S., Flaud, J.-M., Gamache, R. R., Goldmanm, A., Jacquemart, D., Kleiner, I., Lacome, N., Lafferty, W. J., Mandin, J.-Y., Massie, S. T., Mikhailenko, S. N., Miller, C. E., Moazzen-Ahmadi, N., Naumenko, O. V., Nikitin, A. V., Orphal, J., Perevalov, V. I., Perrin, A., Predoi-Cross, A., Rinsland, C. P., Rotger, M., Šimečková, M., Smith, M. A. H., Sung, K., Tashkun, S. A., Tennyson, J., Toth, R. A., Vandaele, A. C., and Vander Auwera, J.: The HITRAN 2008 Molecular Spectroscopic Database, J. Quant. Spectrosc. Rad. Transfer, 110, 533572, 2009.

Roy, D. P., Boschetti, L., Justice, C. O., and Ju, J.: The Collection 5 MODIS Burned Area Product - Global Evaluation by Comparison with the MODIS Active Fire Product, Remote Sens. Environ., 112, 3690-3707, 2008.

Sawyer, G. M., Carn, S. A., Tsanev, V. I., Oppenheimer, C., and Burton, M.: Investigation into magma degassing at Nyiragongo volcano, Democratic Republic of the Congo, Geochem. Geophy. Geosy., 9, Q02017, doi:10.1029/2007GC001829, 2008.

Scholes, R. J., Ward, D. E., and Justice, C. O.: Emissions of trace gases and aerosol particles due to vegetation burning in southern hemisphere Africa, J. Geophys. Res. , 101, 23,677-23, doi:10.1029/95JD02049, 1996.

Scholes, R. J., Gureja, N., Giannecchinni, M., Dovie, D., Wilson, B., Davidson, N., Piggott, K., Mcloughlin, C., Van der Velde, K., Freeman, A., Bradley, S., Smart, R., and Ndala, S.: The environment and vegetation of the flux measurement site near Skukuza, Kruger National Park, Koedoe - Koedoe African Protected Area Conservation and Science44, 73-83, 2001.

Shea, R. W., Shea, B. W., Kauffman, J. B, Ward, D. E., Haskins, C. I., and Scholes M. C.: Fuel biomass and combustion factors associated with fires in savanna ecosystems of South Africa and Zambia, J. Geophys. Res., 101, 23,551-23,568, doi:10.1029/95JD02047, 1996.

Sinha, P., Hobbs, P. V., Yokelson, R. J., Bertschi, I. T., Blake, D. R., Simpson, I. J., Gao, S., Kirchstetter, T. W., and Novakov, T.: Emissions of trace gases and particles from savanna fires in southern Africa, J. Geophys. Res. , 108, 8487, doi:10.1029/2002JD002325, 2003a.

Sinha, P., Hobbs, P. V., Yokelson, R. J., Blake, D. R., Gao, S., and Kirchstetter, T. W.: Distributions of trace gases and aerosols during the dry biomass burning season in southern Africa, J. Geophys. Res., 108, 4536, doi:10.1029/2003JD003691, 2003b.

Sinha, P., Hobbs, P. V., Yokelson, R. J., Blake, D. R., Gao, S., and Kirchstetter, T. W.: Emissions from miombo woodland and dambo grassland savanna fires, J. Geophys. Res., 109, D11305, doi:10.1029/2004JD004521, 2004.

Smith, B. C.: Fundamentals of Fourier Transform Infrared Spectroscopy, CRC Press, Florida, USA, 205 pp., 1996.

Smith, A. M. S. and Wooster, M. J.: Remote classification of head and backfire types from MODIS fire radiative power observations, Int. J. Wildland Fire, 14, 249-254, 2005.

Smith, T. E. L., Wooster, M. J., Tattaris, M., and Griffith, D. W. T.: Absolute accuracy and sensitivity analysis of OP-FTIR retrievals of $\mathrm{CO}_{2}, \mathrm{CH}_{4}$ and $\mathrm{CO}$ over concentrations representative of "clean air" and "polluted plumes", Atmos. Meas. Tech., 4, 97 116, doi:10.5194/amt-4-97-2011, 2011.

Stavrakou, T., Mller, J.-F., De Smedt, I., Van Roozendael, M., van der Werf, G. R., Giglio, L., and Guenther, A.: Evaluating the performance of pyrogenic and biogenic emission inventories against one decade of space-based formaldehyde columns, Atmos. Chem. Phys., 9, 1037-1060, doi:10.5194/acp-9-1037-2009, 2009.

Stocks, B. J., van Wilgen, B. W., Trollope, W. S. W, McRae, D. J., Mason, J. A., Weirich, F., and Potgieter, A. L. F.: Fuels and fire behaviour dynamics on large-scale savanna fires in Kruger National Park, South Africa, J. Geophys. Res. ,101, 23,541-23,550, 1996.

Taylor, J. R.: An Introduction to Error Analysis, University Science Books, Sausalito, CA., 173-180, 1997.

Van der Werf, G. R., Randerson, J. T., Collatz, G. J., and Giglio, L.: Carbon emissions from fires in tropical and subtropical ecosystems, Glob. Change Biol., 9, 547-562, 2003.

van der Werf, G. R., Randerson, J. T., Giglio, L., Collatz, G. J., Mu, M., Kasibhatla, P. S., Morton, D. C., DeFries, R. S., Jin, Y., and van Leeuwen, T. T.: Global fire emissions and the contribution of deforestation, savanna, forest, agricultural, and peat fires (19972009), Atmos. Chem. Phys., 10, 11707-11735, doi:10.5194/acp-10-11707-2010, 2010.

Ward, D. E. and Radke, L. F.: Emission measurements from vegetation fires: a comparative evaluation of methods and results, in: Fire in the Environment: The Ecological, Atmospheric, and Climatic Importance of Vegetation Fires, edited by: Crutzen, P. J. and Goldammer, J. G., Wiley, Chichester, UK, 53-76, 1993.

Ward, D. E., Hao, W. M., Sussot, R. A., Babbit, R. E., Shea, R. W., Kauffman, J. B., and Justice, C. O.: Effect of fuel composition on combustion efficiency and emission factors for African savanna ecosystems, J. Geophys. Res., 101, 23,569-23,576, 1996.

Wooster, M. J., Zhukov, B., and Oertel, D.: Fire radiative energy for quantitative study of biomass burning: Derivation from the BIRD experimental satellite and comparison to MODIS fire products, Remote Sens. Environ., 86, 83-107, 2003.

Wooster, M. J., Roberts, G., Perry, G., and Kaufman, Y. J.: Retrieval of biomass combustion rates and totals from fire radiative power observations: calibration relationships between biomass consumption and fire radiative energy release, J. Geophys. Res. 110, D24311, doi:10.1029/2005JD006318, 2005.

Xu, W., Wooster, M.J., Roberts, G., and Freeborn, P.: New GOES imager algorithms for cloud and active fire detection and fire radiative power assessment across North, South and Central America, Remote Sens. Environ., 114, 1876-1895, 2010.

Yokelson, R. J., Griffith, D. W. T., and Ward, D. E.: Openpath Fourier transform infrared studies of large-scale laboratory biomass fires, J. Geophys. Res., 101, 21,067-21,080, doi:10.1029/96JD01800, 1996.

Yokelson, R. J., Ward, D. E., Susott, R. A., Reardon, J., and Griffith, D. W. T.: Emissions from smoldering combustion of biomass measured by open-path FTIR, J. Geophys. Res. , 102, 18,86518,877, 1997.

Yokelson, R. J., Goode, J. G., Ward, D. E., Susott, R. A., Babbitt, R. E., Wade, D. D., Bertschi, I., Griffith, D. W. T., and Hao, W. M.: Emissions of formaldehyde, acetic acid, methanol, and other trace gases from biomass fires in North Carolina measured by air 5 borne Fourier transform infrared spectroscopy, with 
coincident measurements of aerosol optical depth, J. Geophys. Res., 104, 30,109-30,126, 1999.

Yokelson, R. J., Bertschi, I. T., Christian, T. J., Hobbs, P. V., Ward, D. E., and Hao, W. M.: Trace gas measurements in nascent, aged, and cloud-processed smoke from African savanna fires 30 by airborne Fourier transform infrared spectroscopy, AFTIR, with coincident measurements of aerosol optical depth, J. Geophys. Res., 108, doi:10.1029/2002JD002322, 2003.
Zhukov, B., Lorenz, E., Oertel, D., Wooster, M. J., and Roberts, G.: Spaceborne detection and characterization of fires during the $\mathrm{Bi}$ spectral Infrared Detection, BIRD. experimental small satellite mission 2001-2004, Remote Sens. Environ., 100, 29-51, 2006. 